\title{
74. PERFORMANCE OF THE OCEAN BROADBAND DOWNHOLE SEISMOMETER AT SITE 7941
}

\author{
Toshihiko Kanazawa, ${ }^{2}$ Kiyoshi Suyehiro, ${ }^{3}$ Naoshi Hirata, ${ }^{4}$ and Masanao Shinohara ${ }^{4,5}$
}

\begin{abstract}
The ocean broadband downhole seismometer (OBDS) was successfully emplaced in Hole 794D in the Japan Sea during ODP Leg 128, and OBDS data were obtained continuously aboard JOIDES Resolution during a 60-hr period of real-time observation. During the real-time observation, air-gun profiling was done around Hole 794D using nine ocean-bottom seismometers (OBSs). The OBDS successfully observed air-gun signals from the seismic profiles, five local earthquakes, and an earthquake in Burma $\left(\mathrm{m}_{\mathrm{b}} 5.4\right)$.

Signal-to-noise ratios of air-gun signals and local earthquakes observed by the OBDS are higher by over $20 \mathrm{~dB}$ than those observed by $\mathrm{OBS}$. The epicentral distance of Burma earthquake was $38.99^{\circ}$ to the OBDS. The OBDS could record $P, S$, and some surface waves from this teleseismic event with good signal-to-noise ratio for both the vertical and horizontal components. Broadband seismic noise spectra $(5 \mathrm{~m}-30 \mathrm{~Hz})$ in the ocean region were revealed for the first time by the OBDS observation. The noise level falls between the two levels of noisy and quiet conditions on land above $10 \mathrm{~s}$. The noise level increases toward longer period. Signals from earthquakes larger than $\mathrm{m}_{\mathrm{s}}=6$ at $30^{\circ}$ distance would rise above noise at an 100-s period.

Following the real-time observation, an OBDS seafloor recorder was installed and operated for 30 days in event detection mode and time window mode. There was no triggered event. Very long-period data of 1-hr sampling showed only gradual variations without abrupt steplike changes. This indicates that the clamping we used for the OBDS sensors in the hole was sufficiently stable for such a long-term broadband observation.

The results obtained in this paper strongly suggest that a broadband downhole seismometer performs well and is dispensable for constructing broadband digital seismograph networks on the ocean floor.
\end{abstract}

\section{INTRODUCTION}

Observational seismology has entered a new era with the use of high-performance broadband digital seismographs. Land seismic networks enjoy this technical advance and have been improving their instrumentation toward wide dynamic range and frequency band, with easy data access observation (e.g., IRIS, GEOSCOPE). The new set of data from these observations advances high-resolution seismological studies of the Earth's interior. It has been noted, however, that this new observational window is still limited spatially in the sense that these networks include little of Earth's surface that is covered by water.

There are, however, many difficulties in setting up permanent seismic stations under the sea. These difficulties include the following: (1) Station environment, whether seafloor or borehole observation is required. Station design is also important, whatever the environment. Even if island observations prove to be adequate, vast areas of open ocean will remain (e.g., in the northwestern Pacific). (2) Sustaining stable long-period observation. (3) Retrieving data. (4) Supplying power.

Resolution of these difficulties varies depending on the objectives. More importantly, we lack observational long-period data on which to base our discussion, except for the pioneering experiment of the Columbia-Point Arena Ocean-Bottom Seismic Station (Sutton et al., 1965, 1989).

About $7 \mathrm{yr}$ after the last attempted ocean sub-bottom seismic observation (Duennebier, Stephen, et al. (1987c), a new-generation seismic experiment to emplace an ocean broadband downhole seismometer (OBDS) was successfully conducted on Ocean Drilling

\footnotetext{
' Tamaki, K., Suyehiro, K., Allan, J., McWilliams, M., et al., 1992. Proc. ODP, Sci. Results, 127/128, Pt. 2: College Station, TX (Ocean Drilling Program).

${ }^{2}$ Laboratory for Earthquake Chemistry, Faculty of Science, the University of Tokyo, 7-3-1 Hongo, Bunkyo-ku, Tokyo 113, Japan.

${ }^{3}$ Ocean Research Institute, the University of Tokyo, 1-15-1 Minamidai, Nakano-ku, Tokyo 164, Japan.

${ }^{4}$ Department of Earth Sciences, Faculty of Science, Chiba University, 1-33 Yayoi-cho, Chiba 260, Japan.

${ }^{5}$ Present address: Ocean Research Institute, the University of Tokyo, 1-15-1 Minamidai, Nakano-ku, Tokyo 164, Japan.
}

Program (ODP) Leg 128 in the Japan Sea (Ingle, Suyehiro, et al., 1990). The borehole instrument was installed at $714.5 \mathrm{~m}$ below seafloor (mbsf) within a basalt section near the bottom of Hole 794D. The water depth was $2807 \mathrm{~m}$.

Briefly, the experiment was intended to initiate a seismic broadband observation in the backarc basin of the northern Japan Plate subduction zone to obtain seismic information of the hitherto unprobed crust and upper mantle there. Then, a long-term observation was necessary to capture natural earthquakes larger than moderate size. The seismic sensor is a modified version of a Guralp CMG-3 three-axis feedback-type accelerometer with six-channel outputs of DC-to- $30 \mathrm{~Hz}$ low-gain and $10 \mathrm{~m}$-to- $30 \mathrm{~Hz}$ high-gain acceleration signals. The analog signals are digitized by a 16-bit A/D converter at $80 \mathrm{~Hz} / \mathrm{ch}$ sampling rate and telemetered uphole through the logging cable. Our experiment during Leg 128 consisted of two phases; first, to receive the signals aboard JOIDES Resolution to conduct real-time observation and, second, to connect the logging cable to the seafloor recording system specially constructed for this experiment and deploy it for a long-term observation. During the first phase, an air-gun firing experiment was conducted to detail the crustal structure, including anisotropy together with observation using an ocean-bottom seismometer (OBS) array (Hirata et al., this volume; Shinohara et al., this volume). The seafloor recorder for the second phase was designed to record $60 \mathrm{Mb}$ of selected data triggered by earthquakes and for predetermined time windows after appropriate digital filtering. This data set was retrieved after 8 months in May 1990.

We shall describe in this paper the characteristics of the seismic signal and noise obtained from this experiment with our focus on long-period data.

\section{DATA ACQUISITION \\ Real-Time Experiment}

A digital broadband (DC-30 Hz) seismometer was emplaced in Hole 794D in the Japan Sea on 26 September 1989. The seismometer housing was locked within the basaltic rock section at $714.5 \mathrm{mbsf}$ at a water depth of $2807 \mathrm{~m}$.

Following the installation of the OBDS in Hole 794D, we conducted real-time observation (Fig. 1). The purposes of this observa- 


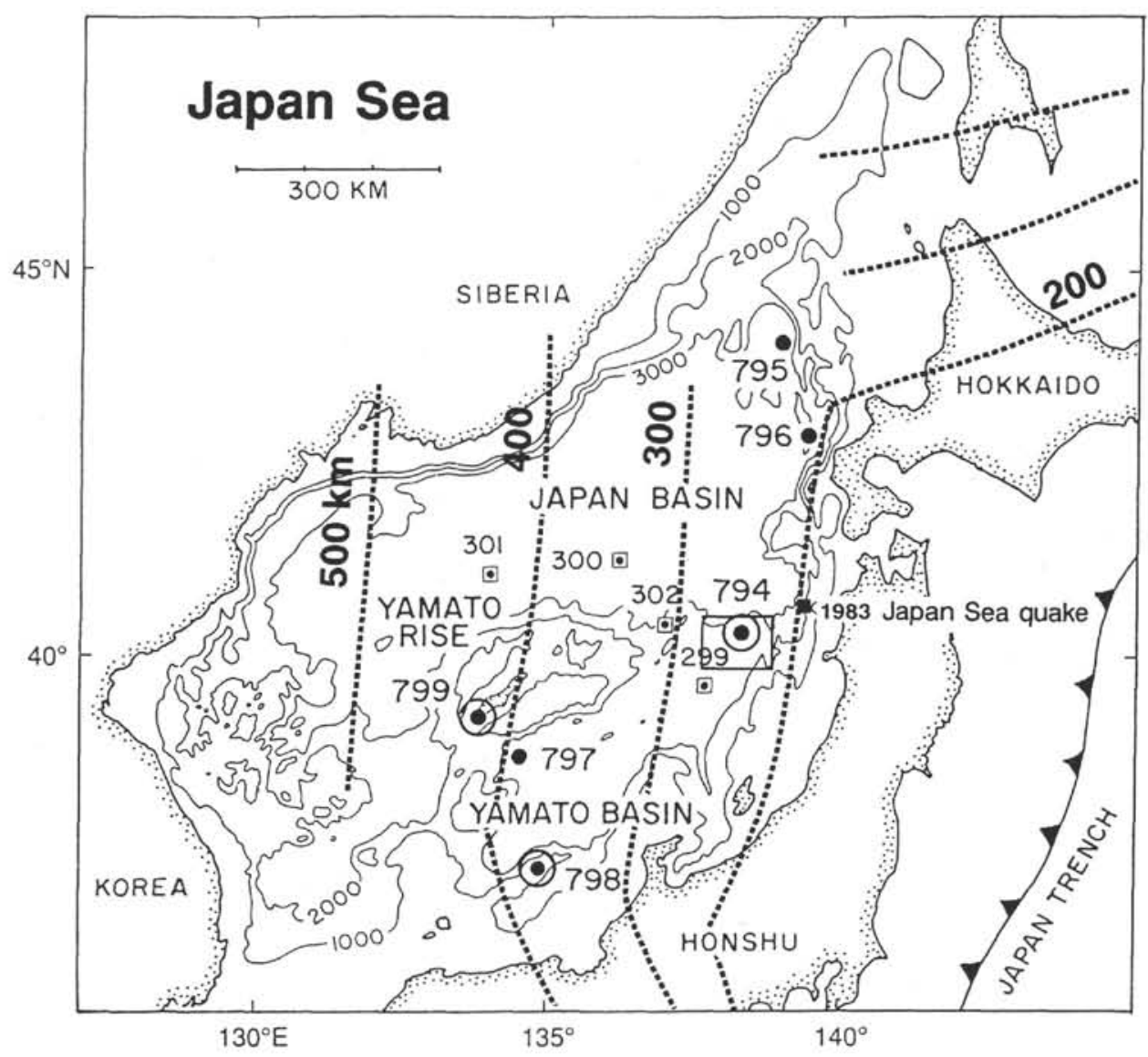

Figure 1. Map showing the Japan Sea (after Ingle, Suyehiro, von Breymann et al., 1990). Circled dots denote Leg 128 sites, and dots show Leg 127 sites. Site 794 was drilled during both legs. Boxed dots indicate DSDP Sites 299 through 302. Bathymetry in meters. Blow-up of squared area is shown in Figure 2. Dotted depth contours indicate Wadati-Benioff zone.

tion were (1) to study the crustal seismic anisotropy in the northern part of the Yamato Basin, (2) to compare the performance of the seismometer in the hole with that on the ocean bottom, and (3) to know the orientation of the horizontal sensors of OBDS. We deployed eight analog- and one digital-recording OBSs on two orthogonal lines and did an air-gun profile experiment about Hole 794D (Fig. 2). It used two 9-L air guns or 17-L air gun on two lines, 70 and $90 \mathrm{~km}$ long, and two circles of $9 \mathrm{~km}$ (inner circle) and $18 \mathrm{~km}$ (outer circle) radius. The shot spacing was about $150 \mathrm{~m}$. The OBDS was positioned at the centers of the circles and the cross point of the two lines.

The OBDS signals were telemetered to the JOIDES Resolution via an electromechanical cable and recorded by the on-board system at an $80-\mathrm{Hz}$ sampling interval. We successfully recovered the nine OBSs. The local crustal structure derived from the experiment is described in Hirata et al. (this volume) and Shinohara et al. (this volume). Unfortunately the digital OBS JRT4H close to Hole 794D did not work well. We had planned to use these records for comparing performance between observations on the seafloor and in the hole. Instead, we used OBS JRT4, an analog-recording OBS deployed close to Hole 794D, as a replacement for this comparison.

\section{Off-Line Experiment}

The seafloor off-line recorder was deployed on the sea bottom near Hole $794 \mathrm{D}$ on 29 September 1989 , succeeding the 60 -hr real-time experiment. In May 1990, we recovered the seafloor system, including a heavy battery unit, without any difficulty. No damage was found to the recovered unit, although the 400 -m nylon rope of $24 \phi$ connected to the seafloor unit for recovery was slightly abraded by the sediments. No electrical corrosion occurred on the surface of the recovered system and the electromechanical cable over about 8 months of deployment. Thus, the mechanical design was ideal for the seafloor off-line recorder and recovery system.

In the recovered $60-\mathrm{Mb}$ tape cartridge, there was no triggered record of an earthquake. In the two-IC memory card of $1 \mathrm{Mb}, 35$-day records of the very long-period (VLP) signals sampled at 1-hr intervals and 245 -hr records of the long-period (LP) signals sampled at 1-min intervals were recorded. A complete description of the OBDS system and the experiments is given in Suyehiro et al. (this volume).

\section{FREQUENCY RESPONSE OF SENSOR AND OVERALL SYSTEM OBDS}

The seismic sensor of the OBDS is a modified version of a Guralp CMG-3 three-axis feedback-type accelerometer. Each component was designed to work within a tilt of $\pm 5^{\circ}$ using a leveling mechanism, because ODP holes were expected to be less than $3^{\circ}$ from vertical. Each component has two acceleration outputs of DC-to- $30 \mathrm{~Hz}$ low gain and $10 \mathrm{~m}$-to- $30 \mathrm{~Hz}$ high gain. The $10 \mathrm{~m}$-to- $30 \mathrm{~Hz}$ acceleration signal is the output of an analog high-pass filter of $10 \mathrm{mHz}$ with a gain of $15.6 \mathrm{~dB}$ to which the low-gain acceleration signal is input. The sensor outputs of the OBDS are fed into a 16-bit analog-to-digital converter with a resolution of $0.34 \mathrm{mV}$ at 1 LSB. Figure 3 is a block diagram of the sensor. Table 1 lists the sensitivities and corner frequencies of sensors. A vertical sensor and a horizontal sensor have 


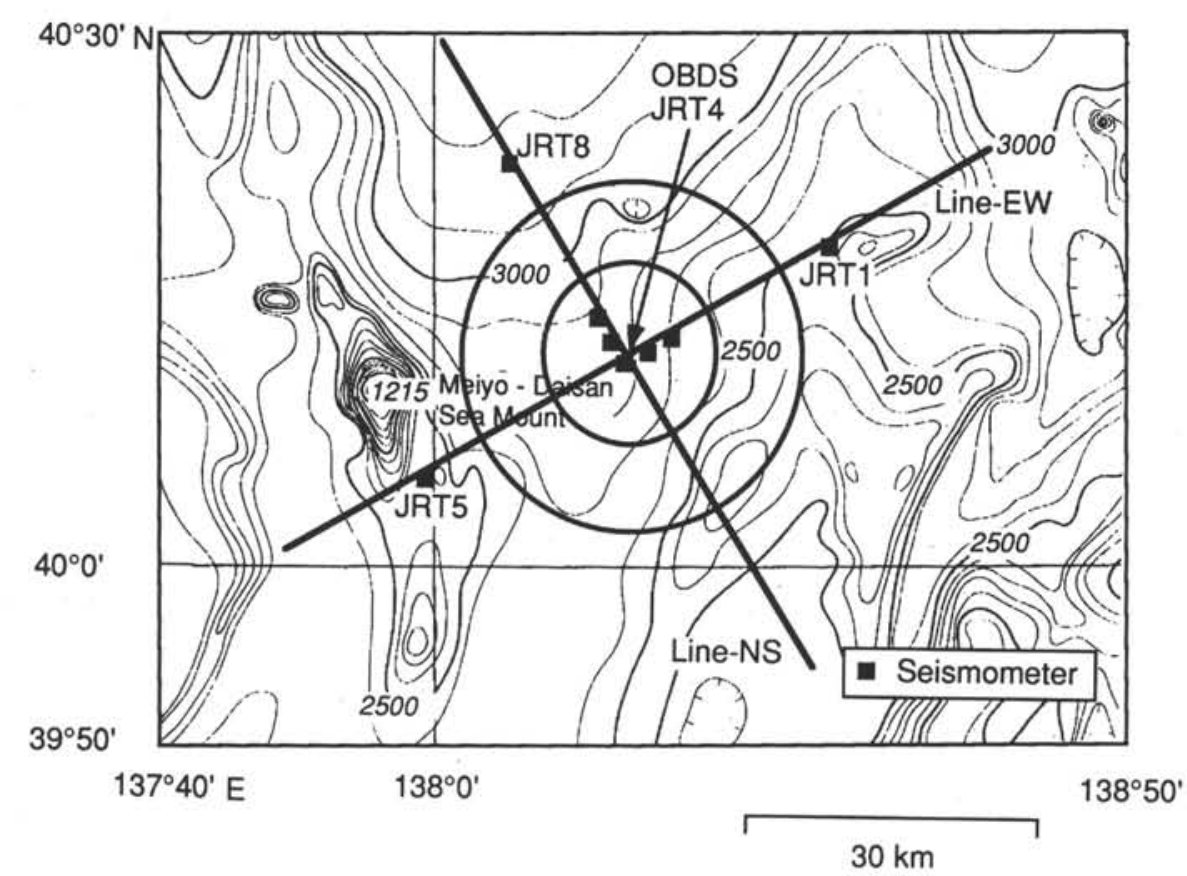

Figure 2. Locations of Hole 794D and the OBDS and OBS array. The OBDS and JRT4 were deployed at Hole 794D. Filled squares show OBSs. The bathymetry contour interval is $100 \mathrm{~m}$. Air-gun profiles were conducted along the two perpendicular lines and two circles.

different mechanical structures; therefore, the responses are somewhat different especially in the high-frequency end. Figure 4 shows the frequency responses for a range of 0.3 to $100 \mathrm{~Hz}$ and the characteristics of the high-pass filter of $10 \mathrm{mHz}$.

\section{OBS}

For comparing OBDS with OBS records in this paper, the characteristics of OBS used in the experiment should be known. We will describe briefly here the recording system and the typical characteristics of the OBS. The OBSs installed around the OBDS were equipped with three-component velocity sensors of $4.5-\mathrm{Hz}$ natural frequency, mounted on a mechanical leveling system (Kanazawa, 1986; Matsuda et al., 1986). Movement of the leveling system with two orthogonal axes was strongly damped by silicon oil. Output signals of the three sensors were amplified with several different gains to raise the dynamic range and recorded by a direct analog recording method. Using a compact, 90-min cassette tape, a continuous 14-day record was made with an ultra-low tape speed of $0.1 \mathrm{~mm} / \mathrm{s}$. The specifications and overall frequency response of the OBS JRT4, the records of which were used for a comparison with the OBDS data, are shown in Table 2 and Figure 5. The frequency response is flat in the range of 5 to $22 \mathrm{~Hz}$ (at $-3 \mathrm{~dB}$ level). The dynamic range is about $40 \mathrm{~dB}$ for each recording channel.

\section{HORIZONTAL SENSOR AZIMUTH}

We had not designed our system to report its orientation. At the time of emplacement we controlled the attitude of OBDS within its sensitive range before clamping in place but did not control the orientation of sensors. Therefore, the sensitive azimuths of the horizontal sensors were to be estimated from measurement of the recorded polarity and the amplitude of the air-gun shots in circles around the hole, such as previously performed by Duennebier, Anderson, et al. (1987) and Anderson et al. (1987).
We used the OBDS data of air-gun shots fired in the inner circle during the real-time observation to determine the azimuths of the horizontal sensors. Figure 6 shows records of the vertical sensor and the horizontal sensor, H2, for air-gun shots on the inner circle. Figure 6 also shows the ratio of the maximum amplitude of the initial phases vs. azimuthal angle. The observed amplitude ratio varies with a period of $180^{\circ}$. The minima are at azimuthal angles of $0^{\circ}$ and $180^{\circ}$. These show that the $\mathrm{H} 2$ sensor is sensitive in the east-west direction. Figure 7 shows records of the $\mathrm{H} 2$ sensor for the shots made along the line. The polarity of the first arrival clearly reversed before and after the air-gun shots passed over the OBDS, with up direction for shots in the eastern portion and down direction for those in the western portion. However, for shots along the north-south line, the polarity change is ambiguous. And the amplitudes of the first arrivals are smaller than those in east-west line. All these facts suggest that the horizontal sensor, $\mathrm{H} 2$, was directed toward the west by about $270^{\circ}$.

\section{VERY LONG-PERIOD DATA}

Very long-period (VLP) data, the low-gain outputs of the OBDS sensors sampled at 1-hr intervals after the application of a digital second-order high-cut filter of $2 \mathrm{hr}$, were recorded in the IC memory card of the seafloor recorder (Fig. 8). The sensor of the OBDS has an automatic mass-centering function to avoid decreasing the dynamic range of its output. However, we had disabled the function to avoid a miscalculation of VLP data that would be caused by mass-centering at an 11-min interval. In exchange for a largely reduced dynamic range, reliable VLP data were recorded during the off-line experiment.

\section{Power Consumption of the System}

One month after installation of the seafloor system, the VLP began to fluctuate abruptly and showed a trapezoid-shaped change of 3 days duration. After records of about 0 count for the next 2 days, VLP records ended on the 35 th day, when the battery deep-discharge 

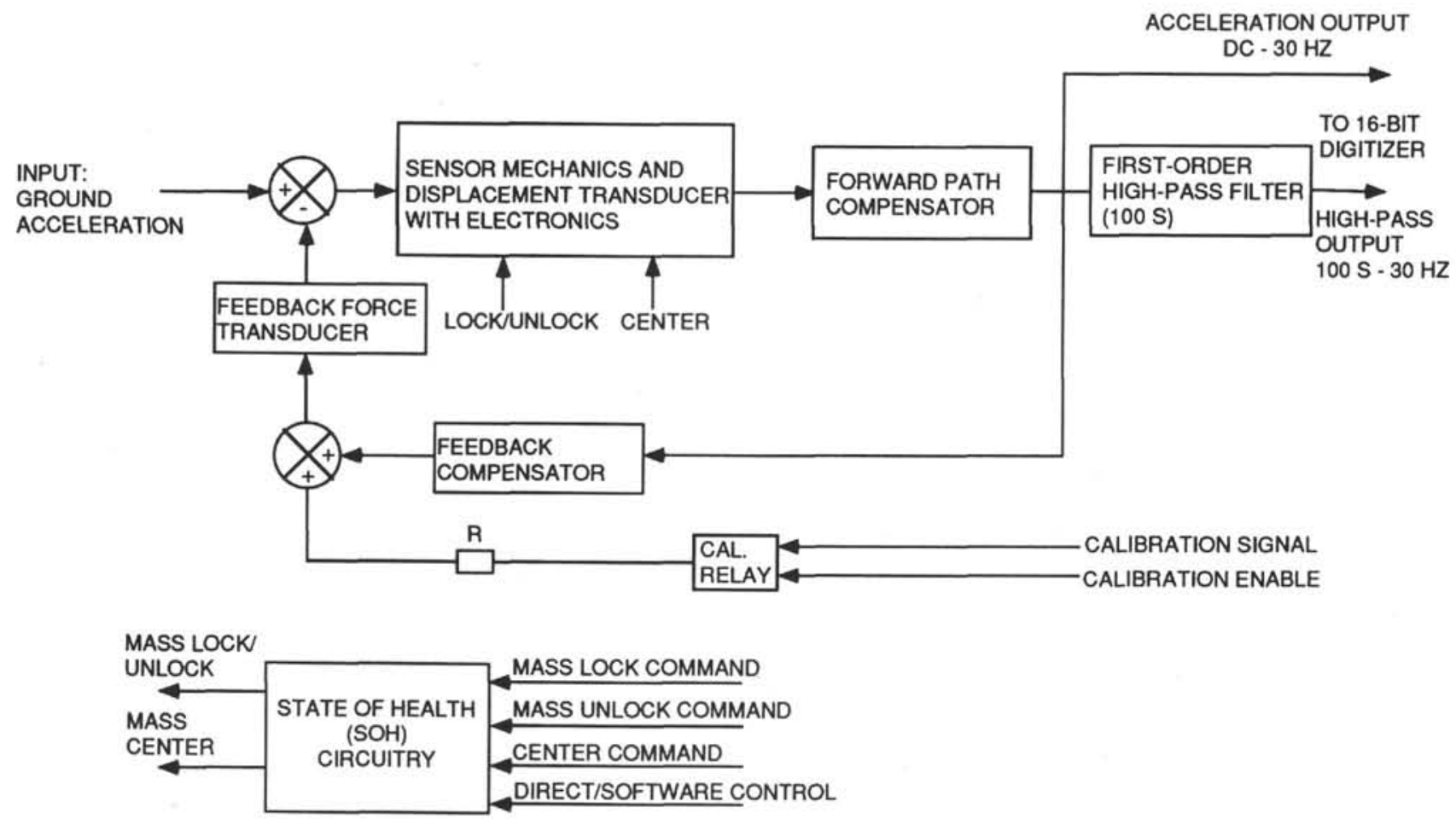

Figure 3. Block diagram of a modified version of CMG-3 accelerometer. The direct output of the sensor is fed into the 16-bit digitizer as the DC-to-30 $\mathrm{Hz}$ low-gain acceleration signal. In parallel, the direct output is fed into a high-pass filter of $10 \mathrm{mHz}$ with a gain of six and digitized as the $10 \mathrm{mHz}$-to- $30 \mathrm{~Hz}$ high-gain acceleration signal. Activating DC voltage to calibration coil by a command will check the sensitivity of the sensor.

Table 1. Sensitivity and corner frequency of the OBDS sensor.

\begin{tabular}{|c|c|c|c|c|}
\hline Sensor & Channel & $\begin{array}{c}\text { Response } \\
(\mathrm{Hz})\end{array}$ & $\begin{array}{l}\text { Sensitivity } \\
\left(\mathrm{V} / \mathrm{m} \cdot \mathrm{s}^{2}\right)\end{array}$ & $\begin{array}{c}\text { Corner } \\
\text { frequency }(\mathrm{Hz})\end{array}$ \\
\hline Vertical sensor & Low gain & DC -30 & 2566 & 44.4 \\
\hline V (\#V380) & High gain & $10 \mathrm{~m}-30$ & 15396 & \\
\hline Horizontal sensor & Low gain & DC -30 & 2700 & 56.0 \\
\hline HI (\#H3133) & High gain & $10 \mathrm{~m}-30$ & 16200 & \\
\hline Horizontal sensor & Low gain & DC -30 & 2854 & 56.0 \\
\hline H2 (\#H3134) & High gain & $10 m-30$ & 17124 & \\
\hline
\end{tabular}

Table 2. Specifications of the OBS JRT4.

\begin{tabular}{|c|c|c|c|}
\hline Sensor & \multicolumn{3}{|c|}{$\begin{array}{l}\text { Three components mounted on a gimbal mechanism } \\
\text { Geospace GS-11D }(4.5 \mathrm{~Hz}, 380 \mathrm{ohm})\end{array}$} \\
\hline \multirow[t]{4}{*}{ Amplifier } & \multicolumn{3}{|l|}{ Low-noise amplifier } \\
\hline & \multirow[t]{2}{*}{ Vertical component } & High-gain channel & $90 \mathrm{~dB}$ \\
\hline & & Low-gain channel & $61 \mathrm{~dB}$ \\
\hline & Horizontal component & Gain & $65 \mathrm{~dB}$ \\
\hline \multirow[t]{2}{*}{ Recorder } & \multicolumn{3}{|c|}{ Direct analog recording, 14 days continuously } \\
\hline & Tape speed & & \\
\hline
\end{tabular}

protection circuit was activated. Vertical and horizontal VLP data show the same fluctuations with time for which the amounts are different. We think that a voltage drop from the power source caused the fluctuations. The sensor CMG- 3 needs $\pm 12 \mathrm{~V}$ to work stably. Other electronic parts in the bottom instrument work at $\pm 5 \mathrm{~V}$. Therefore, the voltage drop affected the sensor first and made it unstable. On the 33 rd day a serious voltage drop occurred and terminated sensor operation. By our estimation, the observation period can possibly be
45 days based on the consumption current of $270 \mathrm{~mA}$ measured in the laboratory. In practice, the observation period was only 30 days. This shows that the consumption current was on the order of $400 \mathrm{~mA}$ during the off-line observation, which was 1.5 times larger than our estimation. VLP data of about 10,000 counts on average (Fig. 8) suggest that the outputs of sensors were about $3.5 \mathrm{~V} \mathrm{DC}$ during the observation. VLP data show that the mass of a sensor was largely off center, which meant that it consumed more electric power than our estimation and shortened the observation period.

\section{Estimation of Temperature Change and Tilting}

The vertical VLP data increased about 14,000 digital counts for the first 10 days after emplacement. Then it decreased by about 6300 digital counts during the next 14 days and became almost stable. The horizontal VLP data show similar changes to the vertical ones with almost the same amount and reversed polarity. Considering a resemblance between the two components, these long-term variations are supposed to be caused by temperature changes in the housing.

The OBDS sensor has a temperature coefficient of about $-180 \mathrm{ppm} /{ }^{\circ} \mathrm{C}$. Using this coefficient value, the variations of the VLP data could be converted to temperature changes inside the housing; a temperature decrease of about $9^{\circ} \mathrm{C}$ for the first 10 days after the emplacement and an increase of about $4^{\circ} \mathrm{C}$ during the next 14 days.

Temperature measurements in Hole 395A, provided by the DARPA downhole seismometer that was emplaced at 609 mbsf, showed a steady increase in temperature, about $1{ }^{\circ} \mathrm{C}$ during 35 days (Becker et al., 1986). Temperature measurements in Hole $581 \mathrm{C}$, by OSSIV which was emplaced about $378 \mathrm{mbsf}$, showed also a steady increase in temperature, about $6^{\circ} \mathrm{C}$ during a 64-day period (Duennebier, Cessaro, et al. (1987). Temperature changes in Hole 794D estimated by VLP data were not a steady increase and larger than the changes in Holes 395A and 581C.

The horizontal sensor is sensitive to tilting of the housing or the hole, because horizontal acceleration is indistinguishable from a small 


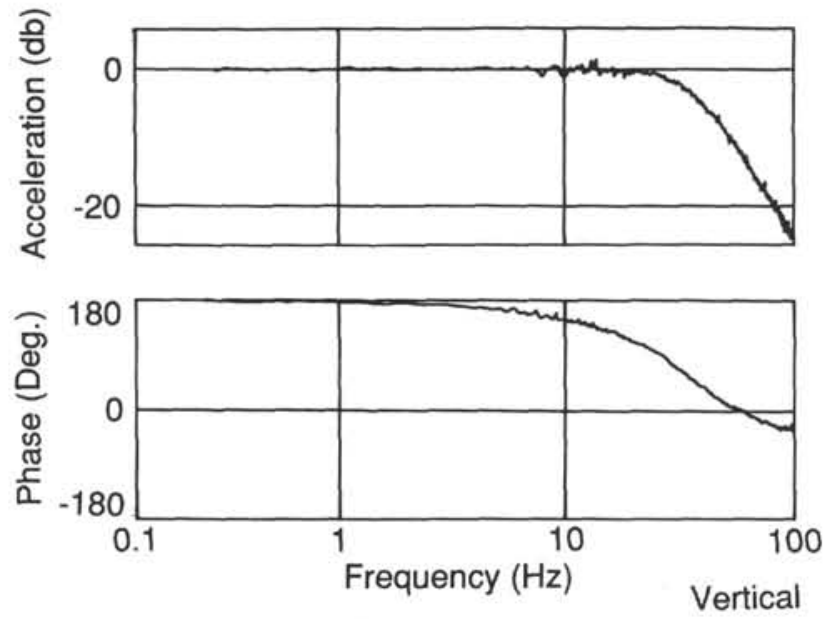

B
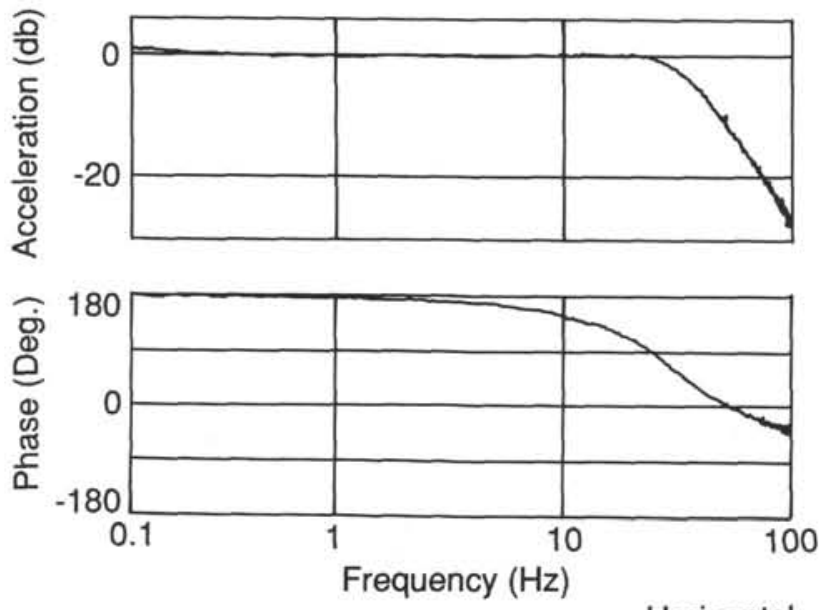

Horizontal

C
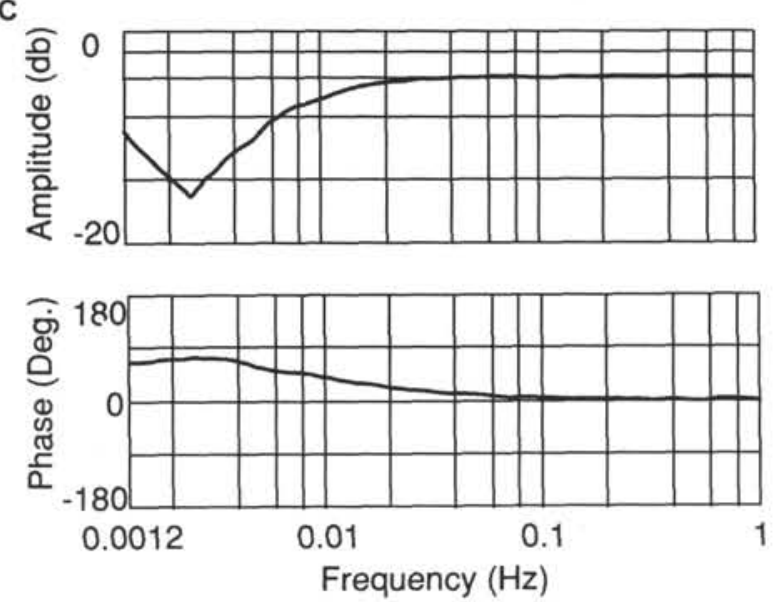

Figure 4. Frequency response of the OBDS sensors. A. The response of the vertical sensor. B. The response of the horizontal sensor. C. The response of the high-pass filter. tilt change. As a tiltmeter, the OBDS horizontal sensor works within $\pm 24.6 \mathrm{mrad}\left( \pm 1.4^{\circ}\right)$ from vertical with a resolution of $0.75 \mu \mathrm{rad}$ (corresponds to 1 digital count). The OBDS vertical sensor is not sensitive to tilting as much as the horizontal sensor. Therefore the tilting of the housing or the hole made a contribution to the horizontal VLP variations. We had no measurement of tilt nor temperature in this study, and therefore we can not distinguish the VLP data separating the contribution of tilting from that of the temperature change.

\section{Stability of OBDS Emplacement}

The method of fixing the instrument in hole is extremely critical for such a long-term broadband observation. The OBDS instrument was clamped in the basaltic rock section at $715 \mathrm{mbsf}$ by pressing against the wall of the hole with an extended pad arm similar to that of OSS IV. As stated above, the OBDS horizontal sensor has a resolution of $0.75 \mu \mathrm{rad}$ as a tiltmeter, and a contribution from tilting of the housing or the hole was contained in the horizontal VLP variations. However, the VLP data shows only gradual variations without abrupt steplike changes. Therefore the tilt variations observed in our experiment were considered to be only gradual ones of which amounts could not be estimated. Considering this fact, the clamping we used for the OBDS sensors had sufficient stability.

\section{LOCAL EARTHQUAKES}

Hole 794D is situated in the region of aftershocks of the 1983 Japan Sea earthquake, $M=7.7$. The OBS JRT4 observed 25 earthquakes during its period of deployment. The OBDS observed five earthquakes among these (Table 3). Several of the earthquakes were located by the seismological network of Tohoku University.

Figures 9, 10, and 11 show the OBDS acceleration records of the earthquakes, \#12, \#18, and \#21, respectively. For direct comparison, the velocity records of the OBS JRT4 close to Hole 794D are also shown in the figures. Figure 12 shows the velocity power spectra of earthquake \#12 observed by the OBDS and the OBS JRT4. The wave shapes of the horizontal sensor of the OBDS are almost similar to those of the vertical sensor, which is the most impressive characteristic of the earthquake records observed by the OBDS. By contrast, the wave shapes of the horizontal sensors of the OBS JRT4 do not resemble those of the vertical sensor because the predominant waves at about $3.5 \mathrm{~Hz}$ were largely excited in the horizontal component of the OBS JRT4. Such features are not observed in the records of the OBDS. The excitation of waves of $3.5 \mathrm{~Hz}$ is considered to be an effect of the soft sediments on which the OBS JRT4 was emplaced. In the record of the vertical component of the OBS JRT4, waves of about $6 \mathrm{~Hz}$ were also excited, but not seen in the OBDS spectra. This might also be an effect of the soft sediments.

The predominant frequency of $S$ arrivals observed by the OBDS is $12.6 \mathrm{~Hz}$, which is longer than the approximate $14 \mathrm{~Hz}$ of $P$ arrivals as seen from land observation (Fig. 12). Other characteristics of the OBDS records are a larger dynamic range of wave shapes, much clearer onsets, better signal-to-noise ratios, and shorter duration of a phase compared to those of the OBS JRT4.

One motivation for emplacing a seismometer beneath the sediments on the ocean bottom was to improve the signal-to-noise ratio for earthquakes (Carter et al., 1984; Cessaro and Duennebier, 1987). The results of OSS II (clamped at 194-m sub-bottom depth in soft sediments) suggest that such an emplacement should avoid the noise associated with the sediment/water interface (Carter et al., 1984). The results showed that OSS IV appeared to be more sensitive than an OBS placed nearby on the ocean floor, in terms of the signal-to-noise ratio (Cessaro and Duennebier, 1987). 


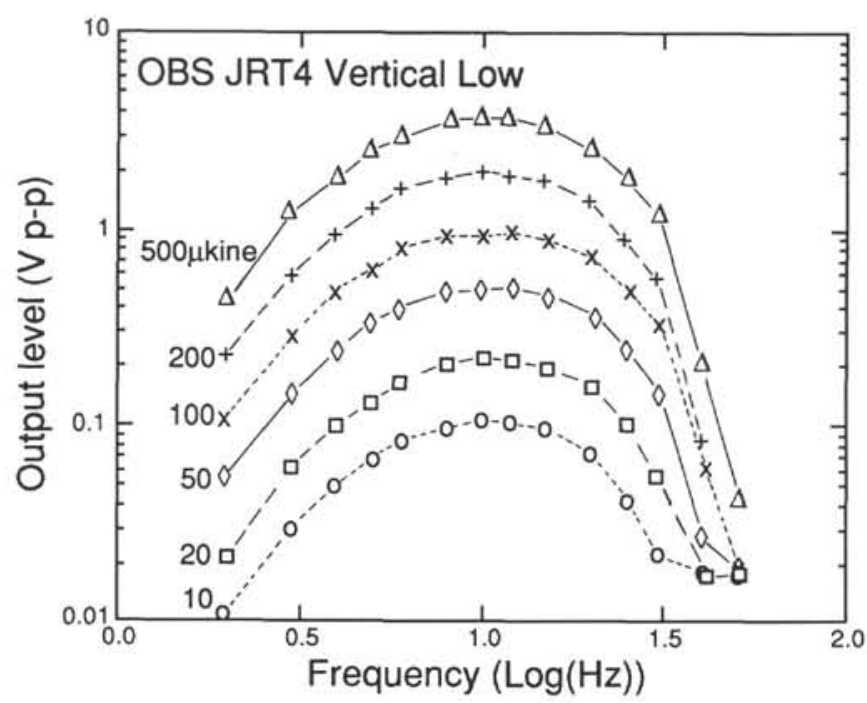

Figure 5. The overall frequency response of the JRT 4 OBS plotted for six levels of velocity.

For our case, during the off-line observation there were no earthquakes observed, so that we do not have sufficient data. However, the OBDS was more sensitive and had higher quality wave shape DATA than the OBS JRT4.

\section{AIR-GUN SIGNALS}

As stated previously, the crustal structure derived from the air-gun profiles conducted during the real-time experiment is described in Hirata et al. (this volume) and Shinohara et al. (this volume). The characteristics of the record sections of the air-gun profiles observed by the OBDS were also described in Shinohara et al. (this volume). Here, we describe dominant features of air-gun records of the OBDS in comparison with those of the OBS JRT4.

Figures 13 and 14 show air-gun records observed by the OBDS and the OBS, respectively. The OBDS could clearly observe initial arrivals; however, the OBS could not. In the record section of the air-gun profiles, seismograms are plotted side by side which raises the signal-to-noise ratio. Therefore, the initial arrivals can be picked up in the OBS record section. But if we compare a seismogram recorded by the OBDS with that by the OBS, the OBDS record has a larger signal-to-noise ratio than the OBS record by more than $20 \mathrm{~dB}$.

\section{TELESEISMIC OBSERVATIONS BY OBDS}

As stated previously, we could not observe any teleseismic events during the off-line observation of 30 days. However, we fortunately observed one teleseismic event of $\mathrm{m}_{\mathrm{b}} 5.4$ (by USGS), which occurred in Burma at 21:52:20.7 UT, 28 September 1989, during the real-time experiment (Table 4). The epicentral distance is $38.99^{\circ}$ to the OBDS. Figure 15 shows the acceleration record of the Burma earthquake for the low-gain outputs of the vertical and the horizontal sensor, H2. Step changes observed at 11-min intervals in the record were caused by the automatic mass-centering activated during the real-time experiment. However, $P, S$, and some surface waves were observed with a good signal-to-noise ratio. The observed maximum amplitude is about $3.6 \mu \mathrm{m} / \mathrm{s}^{2}$. Signals from the earthquake lasted over $100 \mathrm{~min}$. Figure 16 shows part of the surface waves for an expanded time interval. Surface waves dispersed from a period of about 40 to $15 \mathrm{~s}$.
A

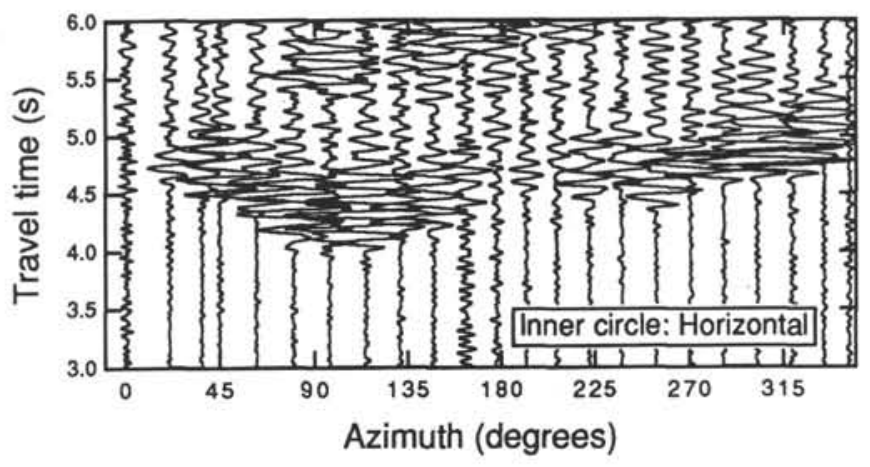

B

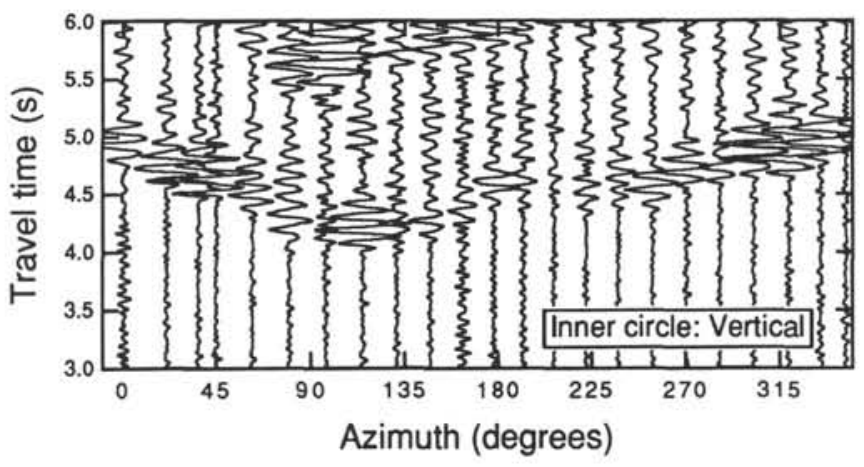

C

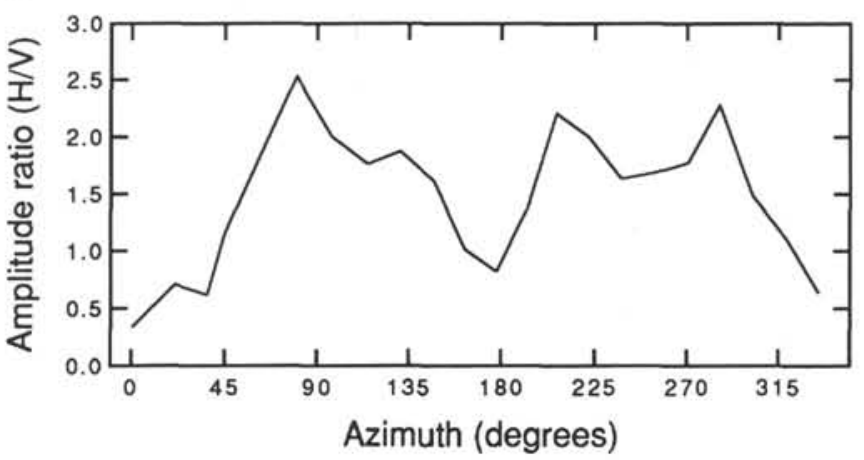

Figure 6. Record sections of the air-gun shots fired in the inner circle. The horizontal axes show the azimuthal angle of the shot position measured from the OBDS. A. Horizontal sensor, H2. B. Vertical sensor. C. Ratio of the maximum amplitudes of the initial phases observed by the horizontal sensor, $\mathrm{H} 2$, and the vertical sensor.

\section{NOISE LEVELS}

In this section we detail our investigation of the frequency spectral contents of the data set obtained by continuous digital recording during the real-time experiment, which lasted from 26 to 29 September 1989. The spectral contents of the available two-component records are similar. Also, the difference between the high- and lowgain channels was simply a constant offset.

Two velocity noise spectra (one-sided power spectral density per unit time) are combined to represent the noise between about $200 \mathrm{~s}$ 
Table 3. Local earthquakes observed by the OBDS durning the real-time experiment (monitored and numbered by OBS JTR4).

\begin{tabular}{lrcc}
\hline Origin time [UT] and epicenter & $\begin{array}{c}\text { Depth } \\
(\mathrm{km})\end{array}$ & Magnitude & $\begin{array}{c}\text { Distance to OBDS } \\
(\mathrm{km})\end{array}$ \\
\hline${ }^{\prime} 129 / 2709: 32$ & & & \\
$\# 149 / 2717: 4928.5340 .613^{\circ} \mathrm{N} 139.373^{\circ} \mathrm{E}$ & 4.0 & & \\
$\# 169 / 2719: 1703.6040 .648^{\circ} \mathrm{N} 139.262^{\circ} \mathrm{E}$ & 6.7 & 1.5 & \\
$\# 189 / 2808: 1426.3040 .481^{\circ} \mathrm{N} 139.275^{\circ} \mathrm{E}$ & 21.5 & 2.4 & 94.3 \\
${ }^{\prime}+219 / 2810: 23$ & & & \\
\hline
\end{tabular}

'Not detected at Tohoku University

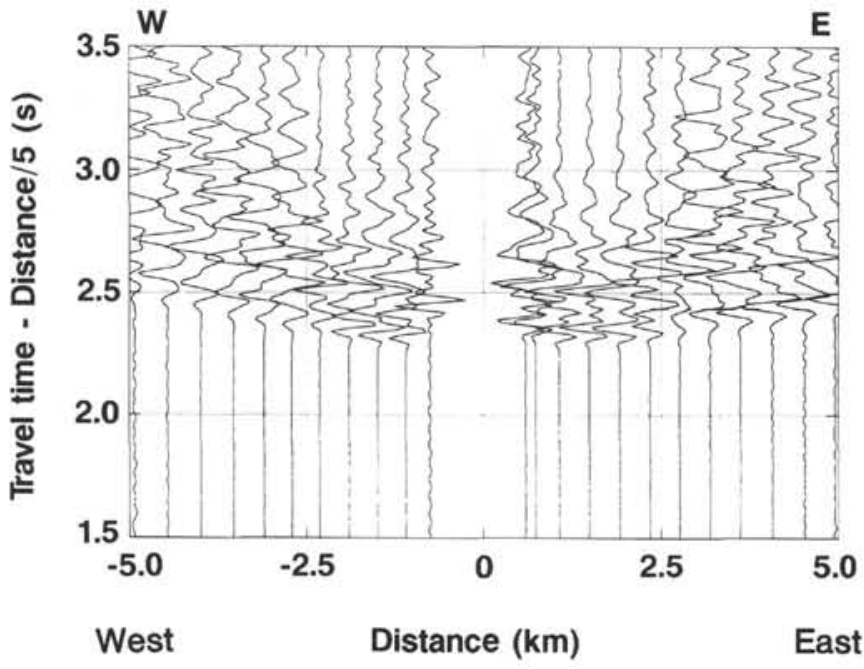

Figure 7. Record section obtained by the horizontal sensor, $\mathrm{H} 2$, of the air-gun shots fired along the east-west line. The horizontal axis shows the epicentral distance.

and $30 \mathrm{~Hz}$ for the horizontal low-gain component (Fig. 17). For the lower frequency range (up to about $2 \mathrm{~s}$ ), an average of four spectra between 06:00 and 10:00 UT, Sept. 27, 1989, each obtained from 8192 samples of 2-Hz high-cut filtered data sampled at a 0.125 -s interval, is plotted. At higher frequency range, an average of four spectra between 21:35 and :38 UT, Sept. 26, 1989, each obtained from 8192 samples of data sampled at a full rate of $80 \mathrm{~Hz}$, is shown. No air-gun energy appears in Figure 17. The weather condition was fair during this period.

The outstanding peak between 0.1 and $1 \mathrm{~Hz}$ consists of two peaks at 0.3 and $0.5 \mathrm{~Hz}$ (Fig. 17). These are different from frequencies of noise due to ocean waves, namely $0.07-\mathrm{Hz}$ noise generated by waves acting on coasts and $0.14-\mathrm{Hz}$ noise due to standing ocean waves, originally explained by Wiechert and Longuet-Higgins (Aki and Richards, 1980). We can find the $0.14-\mathrm{Hz}$ peak on the OBDS spectra, suggesting its origin to be due to standing ocean waves (Fig. 17).

If we compare the OBDS noise power spectra with that of noisy and quiet conditions for a typical station on hard basement rock (Aki and Richards, 1980), we find that the OBDS noise level falls between the two levels on land above $10 \mathrm{~s}$ (Fig. 17). The noise level increases toward the longer period. Signals from earthquakes larger than $\mathrm{m}_{\mathrm{s}}=$ 6 at $30^{\circ}$ distance would rise above noise at a 100 -s period.

Among the few ocean bottom long-period seismic observations (Sutton et al., 1988; Trevorrow et al., 1990; Dozorov and Soloviev, 1991), we compare with the results obtained from the Columbia-Point Arena Ocean Bottom Seismic Station (OBSS) in Figure 17 (Sutton et al., 1988). Their results are comparable to or quieter than other results below $10 \mathrm{~Hz}$ (Dozorov and Soloviev, 1991). The OBDS noise level is lower than OBSS above $0.1 \mathrm{~Hz}$. The increase in OBDS noise level below $0.1 \mathrm{~Hz}$ is probably due to the system and not representing natural noise, because OBDS has only acceleration outputs with a resolution of about $1.2 \times 10^{-7} \mathrm{~m} / \mathrm{s}^{2}$, which is equivalent to about 1.9 $\times 10^{2} \mathrm{~nm} / \mathrm{s}$ at $0.1 \mathrm{~Hz}$.

Figure 18 represents the spectra in displacement. The displacement power density falls at about $43 \mathrm{~dB} /$ decade. This figure may be compared with the noise spectra from Marine Seismic System (MSS) and quiet continental sites at Queen Creek, Arizona, and Lajitas, Texas (Adair et al., 1986), and Seismic Research Observatory (SRO) station on Guam island (GUMO) (Hedlin and Orcutt, 1989). We chose GUMO data for comparison because this station was quieter than Taiwan and Easter Island stations as discussed by Hedlin and Orcutt (1989), who found that island stations and OBS or MSS noise spectra are comparable between 0.1 and $10 \mathrm{~Hz}$, and thus, seafloor stations are practical where there are not nearby islands for stations.

The OBDS is quieter than MSS below $0.1 \mathrm{~Hz}$ and quieter than GUMO above about $0.15 \mathrm{~Hz}$. Below $0.1 \mathrm{~Hz}$, island stations show a reduction in displacement power, whereas the OBDS does not because of the resolution problem given above. Still at the low-frequency band above about $0.01 \mathrm{~Hz}$, the OBDS is capable of capturing large global earthquakes or intermediate events at teleseismic distances as exemplified by the teleseismic event record.

The temporal change of the acceleration power spectral density is shown in Figure 19D. This was obtained by contouring the spectra calculated for 8192 samples at 0.125 -s intervals starting at hour intervals from 06:00 UT, 27 September to 03:00 UT, 29 September. A decade change in power spectral density level corresponds to a gray-scale level change. The conspicuous spectra at 22:00 UT, 28 September is the result of an earthquake (Fig. 15).

When we compare this with the sea state and atmospheric pressure (Fig. 19A, B), we see that above about $0.3 \mathrm{~Hz}$, the change corresponds to the change in pressure and sea state except for swell height. Apparently, below this frequency, the noise level is not affected by these factors. Figure $19 \mathrm{C}$ was obtained by calculating the mean values of 4096 samples at about 51-s intervals and substituting DC offsets caused by the $11-\mathrm{min}$ mass centering function by interpolations. The vertical component does not seem to be affected by the weather, whereas the horizontal component seems to have changed its trend at a maximum in atmospheric pressure rate, although its physical relationship is not clear.

\section{CONCLUSIONS}

We analyzed the observed records of the OBDS during phase 1, the real-time observation, and phase 2 , the off-line observation, to clarify its performance. We also analyzed the observed records of the OBS JRT4, which was emplaced close to the OBDS to compare the performance of the OBDS in the hole with the observation from the seafloor.

The following results were obtained in this study.

1. The orientation of the horizontal sensors was successfully determined by analyzing the records of air-gun profiles conducted during the phase 1 . The horizontal sensor, $\mathrm{H} 2$, was directed toward the west by about $270^{\circ}$, and $\mathrm{Hl}$ was directed toward the south.

2. The method of fixing the instrument in hole is extremely critical for such a long-term broadband observation. The OBDS instrument was clamped in the basaltic rock section at 715 mbsf by pressing against the wall of the hole with an extended pad arm. The clamping performed well with sufficient stability.

3. Comparison between the records of the OBDS and the OBS JRT4 for local earthquakes and air-gun signals shows that the OBDS had higher quality wave shapes and a larger signal-to-noise ratio of more than $20 \mathrm{~dB}$ greater than that of the OBS.

4. The OBDS could record $P, S$, and dispersed surface waves with good signal-to-noise ratios for the vertical and horizontal components from a teleseismic event of a magnitude $m_{b} 5.4$ that occurred in Burma on September 28,1989 . The epicentral distance was $38.99^{\circ}$ to the OBDS.

5 . The seismic noise spectrum was revealed for the first time in broadband $(5 \mathrm{~m}-30 \mathrm{~Hz})$ in the sea region by our OBDS observation. 


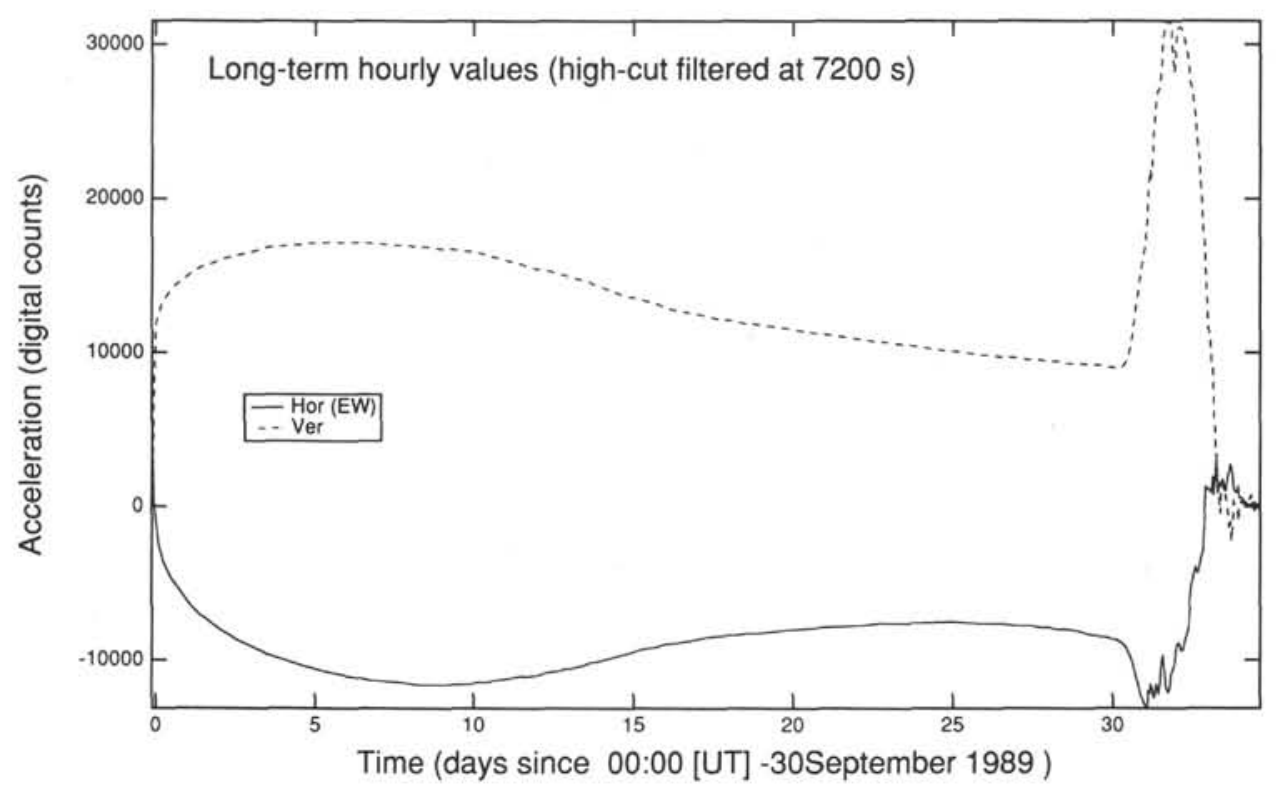

Figure 8. Record section of VLP data for the OBDS sensors.

The noise level falls between the two levels of noisy and quiet conditions on a hard basement rock on land above $10 \mathrm{~s}$. Comparisons with previous islands, seafloor, or borehole observations at frequencies above $0.1 \mathrm{~Hz}$ showed that the OBDS site was relatively quiet. The noise level increases toward a longer period, which is probably determined by the system.

The results obtained in this paper strongly suggest that a broadband downhole seismometer is a high-performance solution for constructing broadband digital seismograph networks on the ocean floor.

\section{ACKNOWLEDGMENTS}

We thank the staffs and the crews of JOIDES Resolution, Tanseimaru, Kaiko-maru 5, and Wakashio-maru for their contributions to the experiments. We owe very much to the ODP engineers and technicians and Schlumberger engineer aboard JOIDES Resolution for Leg 128. We thank all the shipboard scientists, including H. Kinoshita, H. Shiobara, and A. Nishizawa.

\section{REFERENCES}

Adair, R. G., Orcutt, J. A., and Jordan, T. H., 1986. Analysis of ambient seismic noise recorded by downhole and ocean-bottom seismometers on Deep Sea Drilling Project Leg 78B. In Hyndman, R. D., Salisbury, M. H., et al., Init. Repts, DSDP, 78B: Washington (U.S. Govt. Printing Office), 767-781.

Aki, K., and Richards, P., 1980. Quantitative Seismology (Vol. 1): New York (Freeman), 497-498.

Anderson, P. N., Duennebier, F. K., and Cessaro, R. K., 1987. Ocean borehole horizontal seismic sensor orientation determined from explosive charges. J. Geophys. Res., 92:3573-3579.

Becker, K., Langseth, M. G., and Hyndman, D., 1986. Temperature measurements in Hole 395A, Leg 78B. In Hyndman, R. D., Salisbury, M. H., et al., Init. Repts. DSDP, 78B: Washington (U.S. Govt. Printing Office), 767-781.

Carter, J. A., Duennebier, F. K., and Hussong, D. M., 1984. A comparison between a downhole seismometer and a seismometer on the ocean floor. Bull. Seismol. Soc. Am., 74:763-772.
Cessaro, R. K., and Duennebier, F., 1987. Regional earthquakes recorded by ocean bottom seismometers (OBS) and an ocean sub-bottom seismometer (OSS IV) on Leg 88. In Duennebier, F. K., Stephen, R., et al., Init. Repts. DSDP, 88: Washington (U.S. Govt. Printing Office), 129-145.

Dozorov, T. A., and Soloviev, S. L., 1991. Spectra of ocean-bottom seismic noise in the $0.01-10 \mathrm{~Hz}$ range. Geophys. J. Int., 106:113-121.

Duennebier, F. K., Anderson, P. N., and Fryer, G. J., 1987. Azimuth determination of and from horizontal ocean bottom seismic sensors. J. Geophys. Res., 92:3567-3572.

Duennebier, F. K., Cessaro, R. K. and Harris, D., 1987. Temperature and tilt variation measured for 64 days in Hole 581C. In Duennebier, F. K., Stephen, R., Gettrust, J. F., et al., Init. Repts. DSDP, 88: Washington (U.S. Govt. Printing Office), 161-165.

Duennebier, F. K., Stephen, R., Gettrust, J. F., et al., 1987. Init. Repts. DSDP, 88: Washington (U.S. Govt. Printing Office).

Hedlin, M.A.H., and Orcutt, J. A., 1989. A comparative study of island, seafloor, and subseafloor ambient noise levels. Bull. Seis. Soc. Am., 79:172-179.

Ingle, J. C., Jr., Suyehiro, K., von Breymann, M., et al., 1990. Proc. ODP, Init. Repts., 128: College Station, TX (Ocean Drilling Program).

Jeffreys, H., and Bullen, K. E., 1940. Seismological Tables: British Association, Gray-Milne Trust.

Kanazawa, T., 1986. Ocean bottom seismometer with low power design. Annu. Meet. Seismol. Soc. Jpn. Abstr., 2:240. (Abstract in Japanese)

Matsuda, N., Fujii, T., and Kinoshita, H., 1986. Pop up ocean bottom seismometer with hydrophone system. Annu. Meet. Seismol. Soc. Jpn. Abstr., 2:241. (Abstract in Japanese)

Sutton, G. H., Barstow, N., and Carter, J. A., 1988. Long-period seismic measurements on the ocean floor. In Proc. Workshop on Broad-band Downhole Seismometers in the Deep Ocean. Woods Hole Oceanogr. Inst., 126-142.

Sutton, G. H., McDonald, W. G., Prentiss, D. D., and Thanos, S. N., 1965. Ocean-bottom seismic observatories. Proc. IEEE, 53:1909-1921.

Trevorrow, M. V., Yamamoto, T., Turgut, A., Goodman, D., and Badiey, M., 1990. Very low frequency ocean bottom ambient seismic noise and coupling on the shallow continental shelf. Mar. Geophys. Res., 11:129-152.

Date of initial receipt: 8 May 1991

Date of acceptance: 28 February 1992

Ms 127/128B-236 

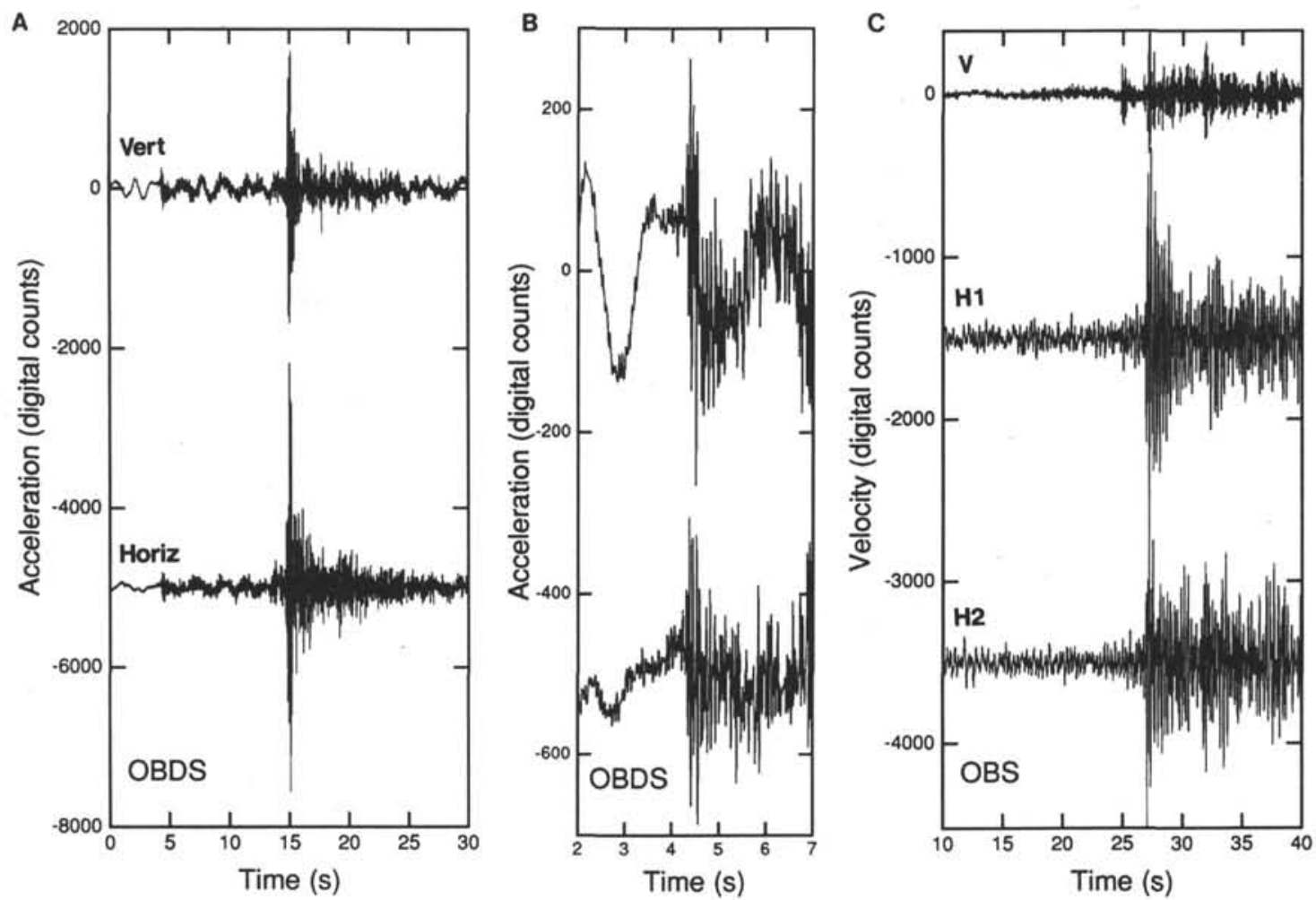

Figure 9. Records of the earthquake \#12 (Table 3). A. Acceleration records from the OBDS. High-gain outputs of vertical and horizontal sensors are shown. B. $P$-wave acceleration records from the OBDS, with an expanded time scale. C. Velocity records for vertical low-gain output and horizontal outputs, $\mathrm{H} 1$ and $\mathrm{H} 2$, from the OBS JRT4.

A

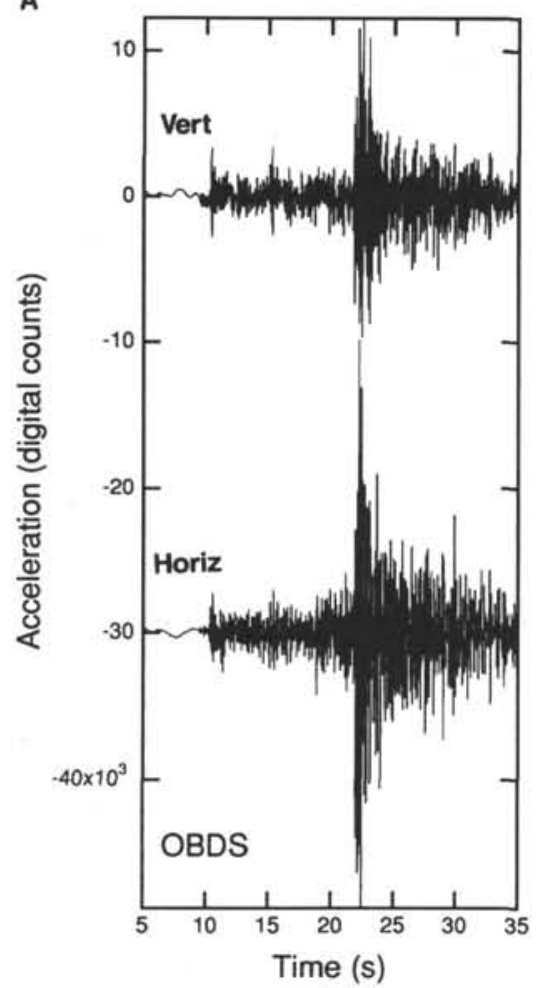

B

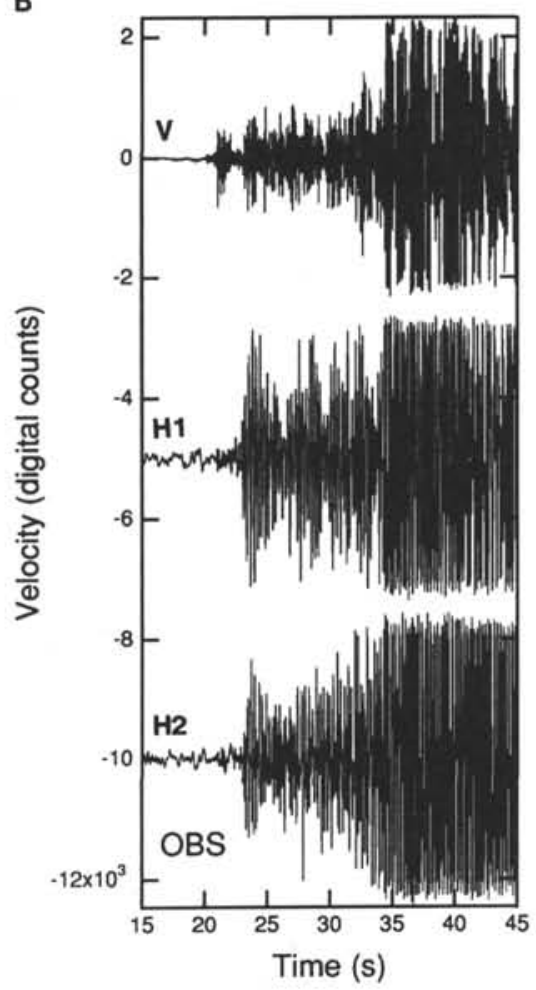

Figure 10. Records of the earthquake \#18 (Table 3). A. Acceleration records for the high-gain outputs of vertical and horizontal sensors observed by the OBDS. B. Velocity records of vertical low-gain output and horizontal outputs, $\mathrm{H1}$ and $\mathrm{H} 2$, observed by the OBS JRT4. $S$ waves are saturated on all traces. 

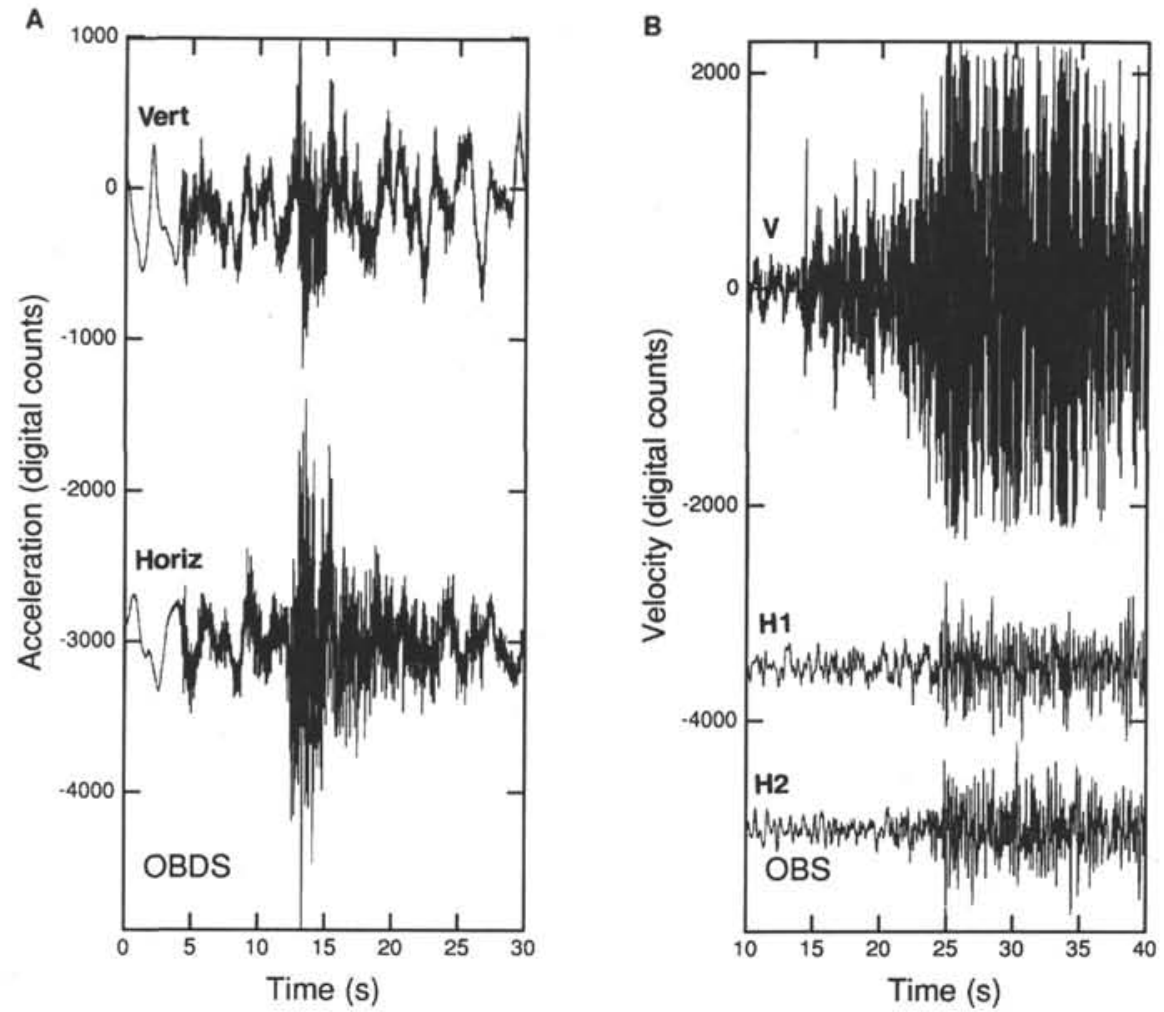

Figure 11. The records of the earthquake $\# 21$ (Table 3). A. Acceleration records for the high-gain outputs of vertical and horizontal sensors observed by the OBDS. B. Velocity records of vertical high-gain output and horizontal outputs, $\mathrm{H1}$ and $\mathrm{H} 2$, from the OBS JRT4. $S$ waves on the vertical trace are saturated.
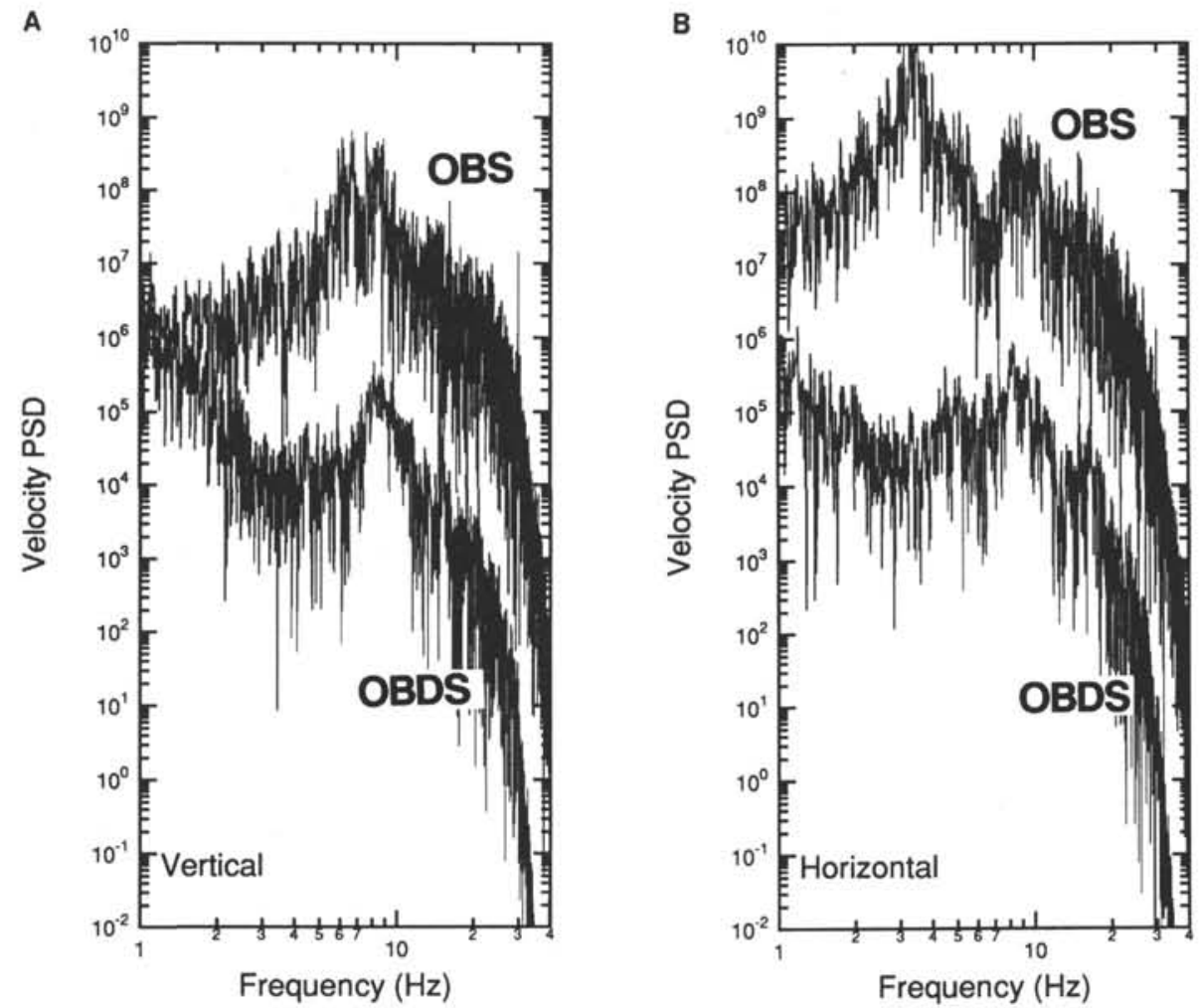

Figure 12. The velocity power spectra of earthquake \#12 (Table 3). A. Velocity power spectra of the OBDS vertical high-gain output and the JRT4 vertical low-gain output around $P$-wave arrivals. OBS velocity response was assumed flat, so frequency range of 5 to $22 \mathrm{~Hz}$ is within $3 \mathrm{~dB}$ change (Fig. 5). For direct level comparison, OBS curve should be lowered by about $26 \mathrm{~dB}$ in power. B. Velocity power spectra of the OBDS horizontal high-gain output and the JRT4 horizontal output, H1, around $S$ - wave arrivals. 
A

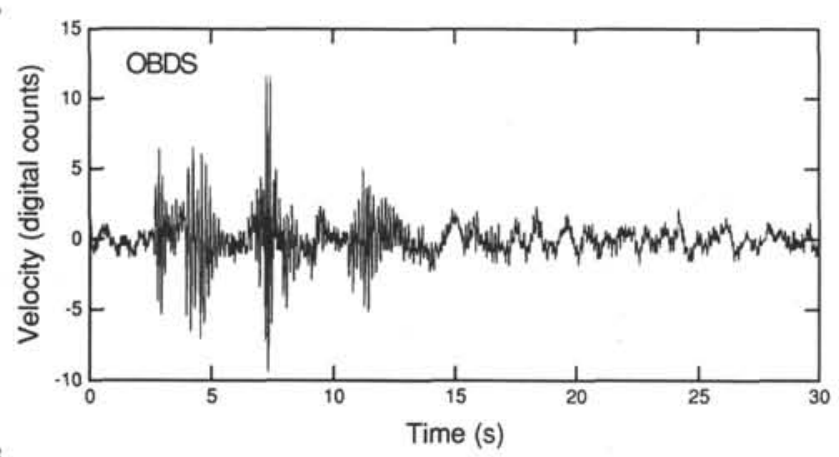

B

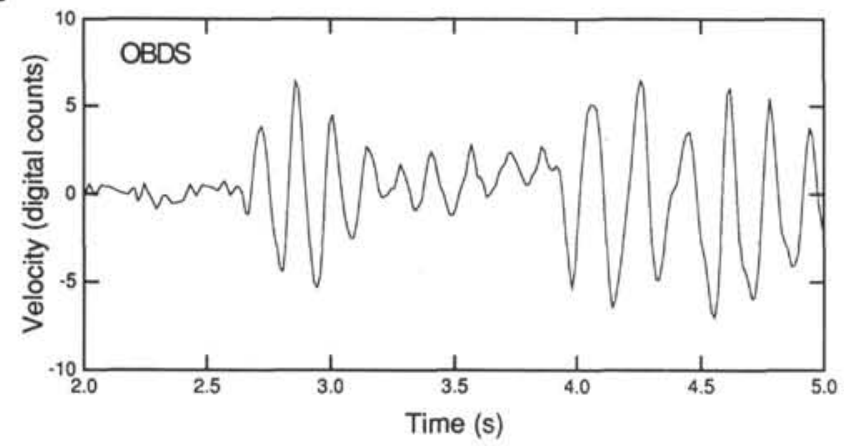

Figure 13. Record of air-gun shot \#160 of the north-south line observed by the OBDS at a distance of $7.99 \mathrm{~km}$. A. Velocity record of the vertical high-gain output applied by a $5-\mathrm{Hz}$ high-pass filter. B. The same velocity record with an expanded time scale.
A
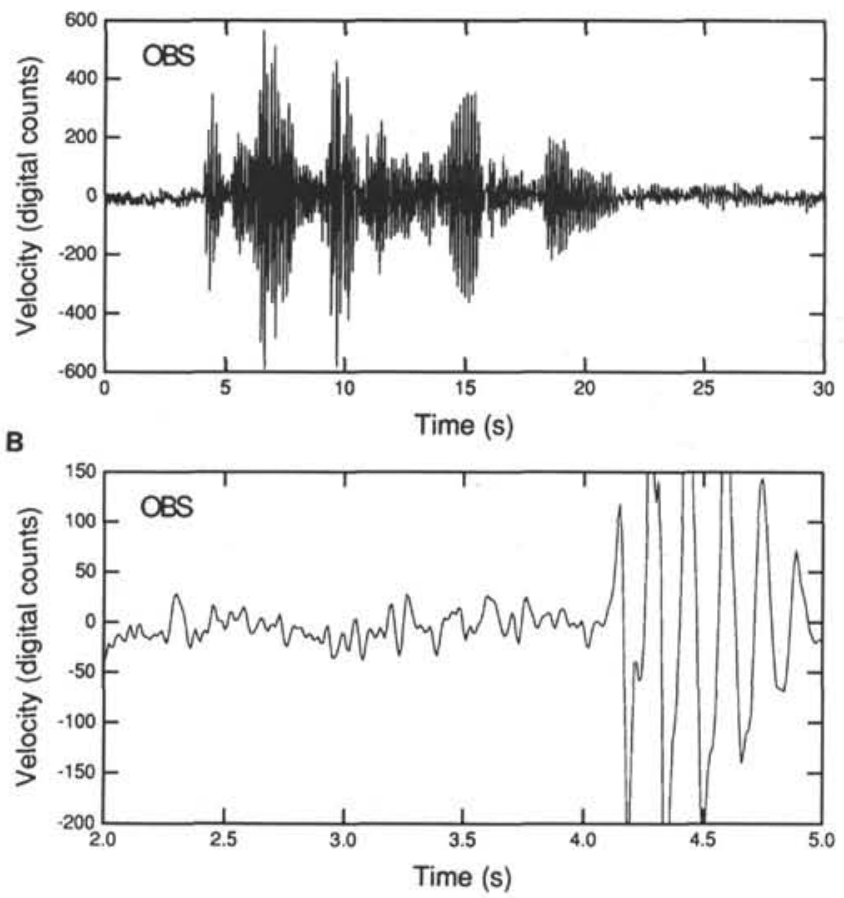

Figure 14. Record of air-gun shot \#160 of the north-south line observed by the OBS at a distance of $7.62 \mathrm{~km}$. A. Velocity record of the vertical low-gain output. B. The same velocity record with an expanded time scale.

Table 4. Teleseismic event observed by the OBDS (determined by USGS).

\begin{tabular}{lcc}
\hline Origin time [UT] & $9 / 2821: 5220.7$ & \\
Hypocenter & $20.313^{\circ} \mathrm{N} 98.809^{\circ} \mathrm{E}$ & $33 \mathrm{~km}$ Burma \\
Magnitude & $\mathrm{m}_{\mathrm{b}} 5.4$ & \\
Distance to OBDS & $38.99^{\circ}$ & \\
Traveltime from Jeffreys & $P:$ & $8 \mathrm{~min} .6 \mathrm{~s}$ \\
and Bullen table (1940) & $S:$ & $14 \mathrm{~min} .35 \mathrm{~s}$ \\
\hline
\end{tabular}




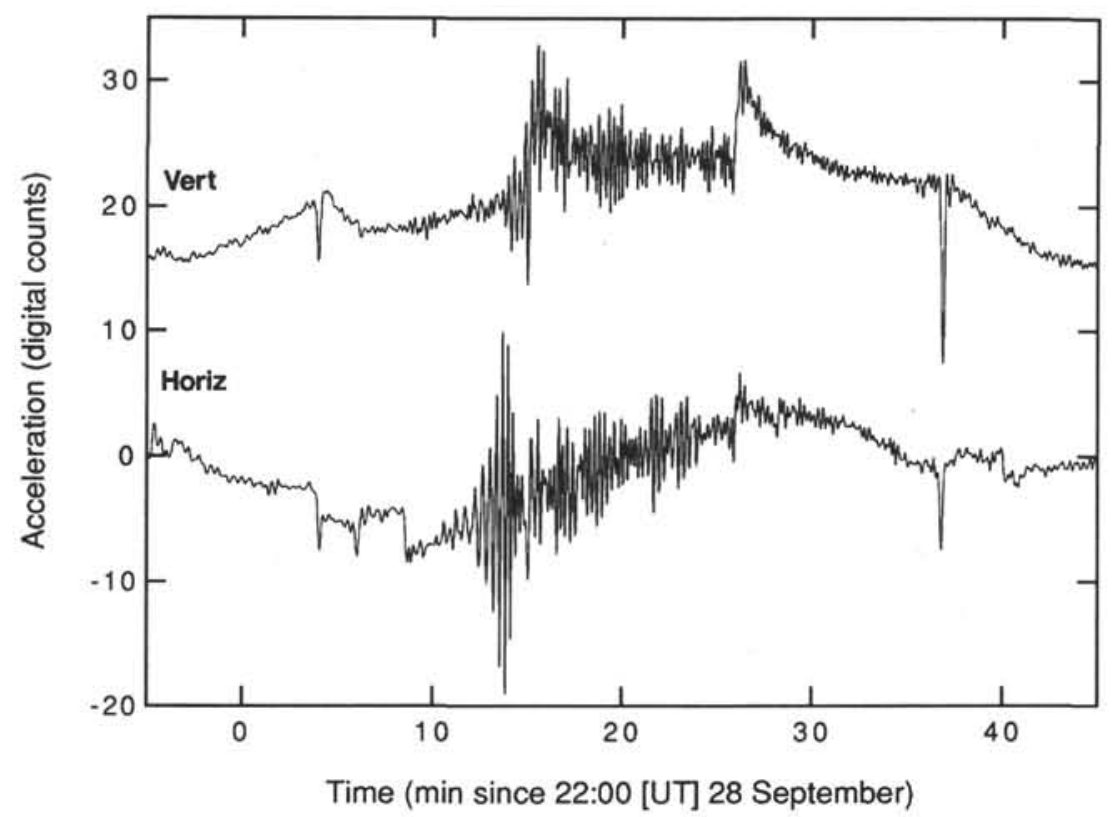

Figure 15. OBDS record of a teleseismic event of $m_{b} 5.4$ (USGS record) that occurred in Burma. The low-gain outputs of the vertical and horizontal sensor, $\mathrm{H} 2$, are shown. Cyclic changes observed at 11-min intervals were caused by the automatic mass-centering function.

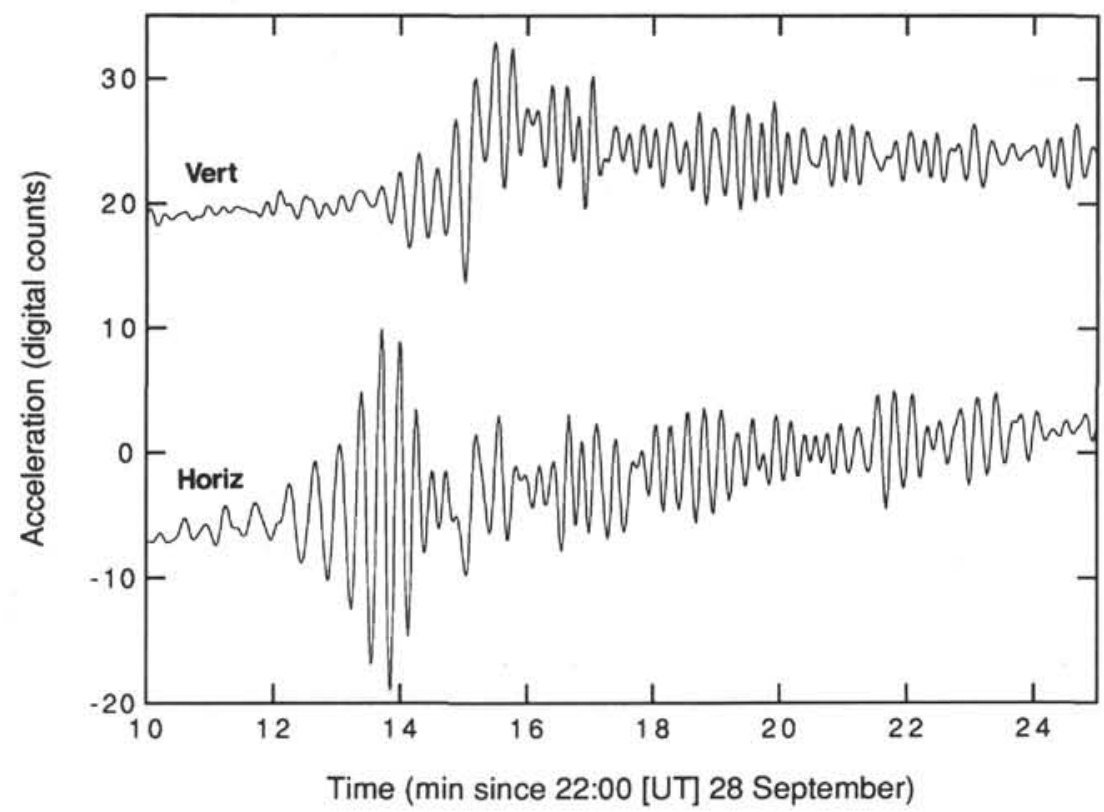

Figure 16. OBDS record of surface waves from a teleseismic event in Burma (the same record as Fig. 15). The waves disperse from a period of about 40 to $15 \mathrm{~s}$. 
A

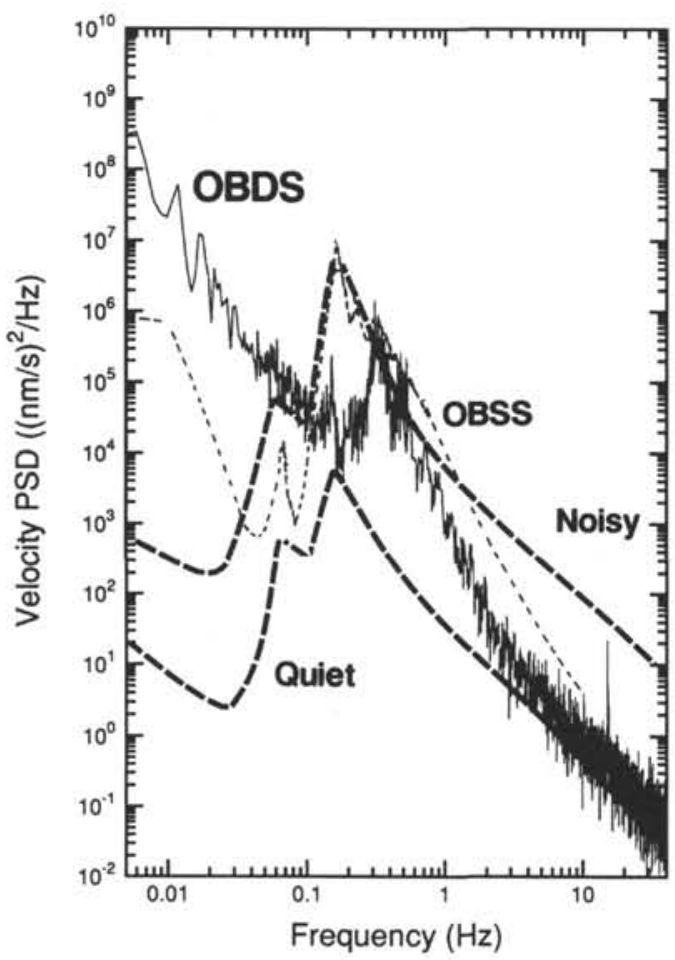

B

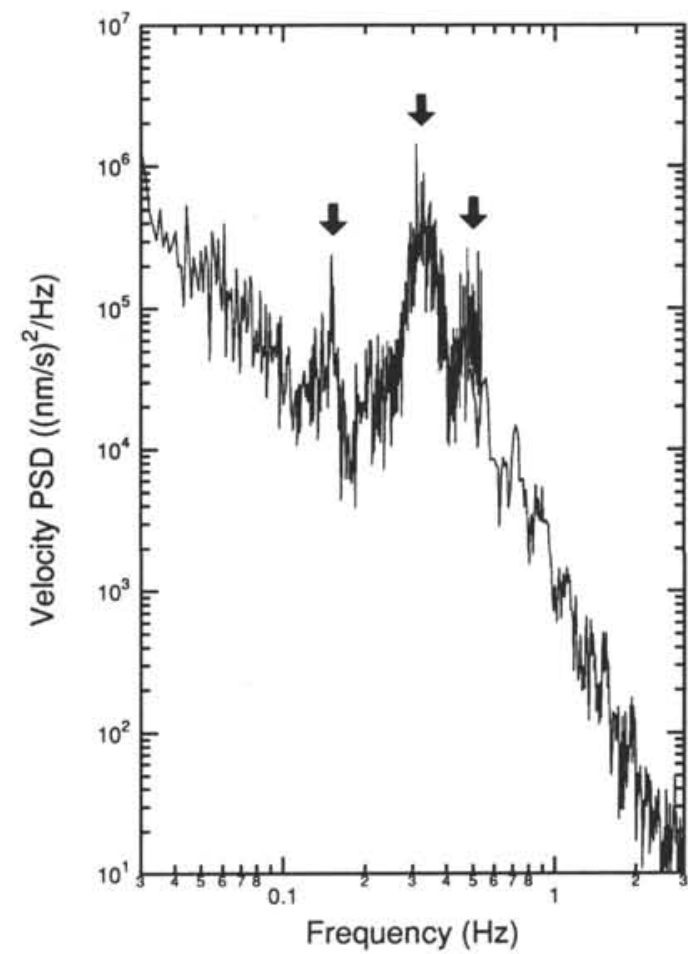

Figure 17. Velocity power spectral density per unit time (one-sided) obtained from OBDS horizontal low-gain component. A. OBDS curve for frequencies below about $0.5 \mathrm{~Hz}$ is the mean of four 1022-s-long data sets between 06:00 and 10:00 UT on 27 September 1989. The mean of four 102-s-long data sets between 21:35 and 21:38 UT on 26 September is plotted for frequencies above about $0.5 \mathrm{~Hz}$. Also shown are typical land noise curves from Aki and Richards (1980). Dotted curve is vertical-component spectra of OBSS at a quiet period from Sutton et al. (1988). B. Expanded plot of A showing three spectral peaks. The leftmost peak is at about $0.14 \mathrm{~Hz}$. 


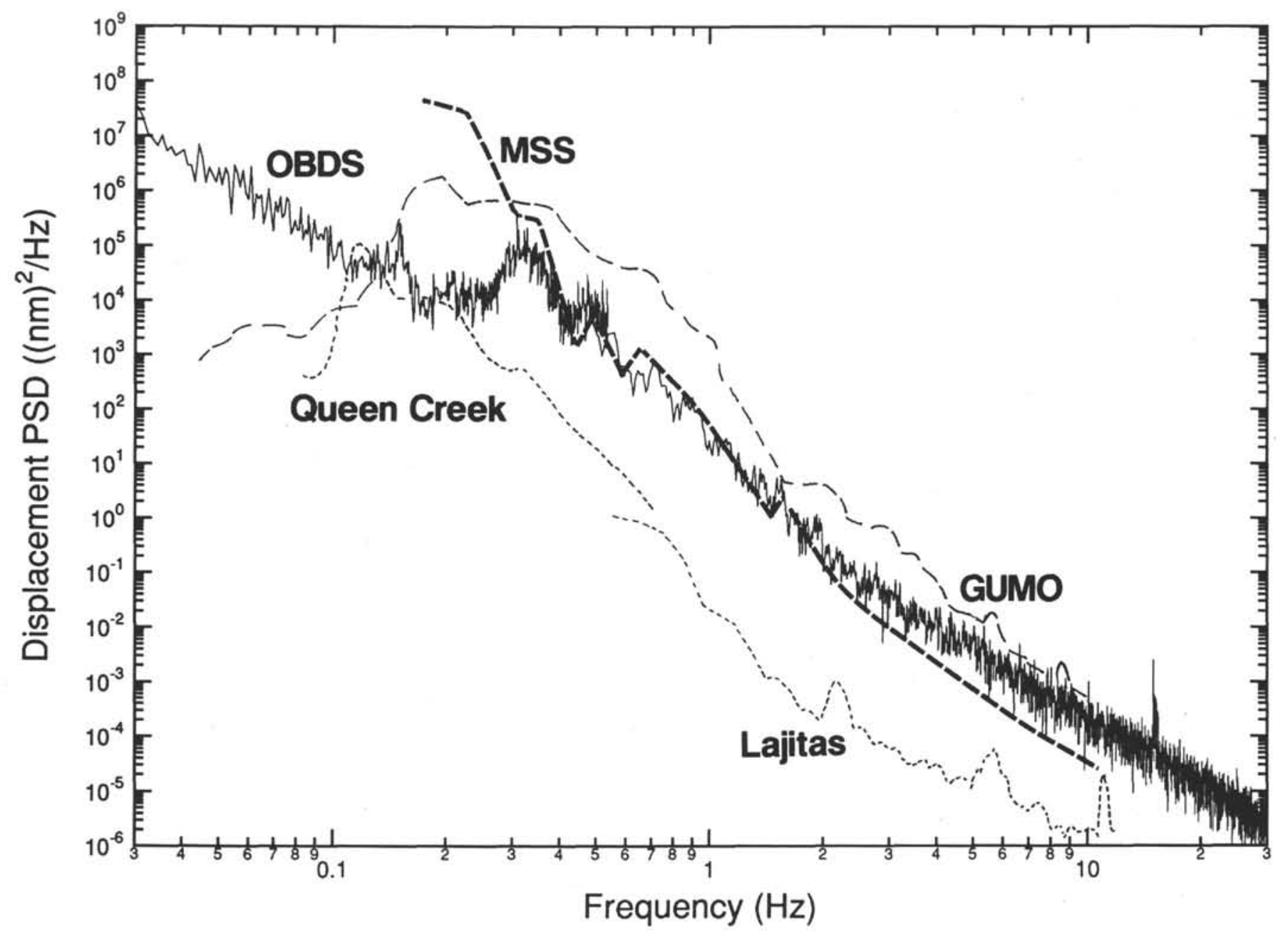

Figure 18. Displacement power spectral representation of Figure 17. Displacement power decay is about $43 \mathrm{~dB} /$ decade. Also shown for comparison are MSS, Queen Creek, and Lajitas from Adair et al. (1986), and GUMO from Hedlin and Orcutt (1989). 
A

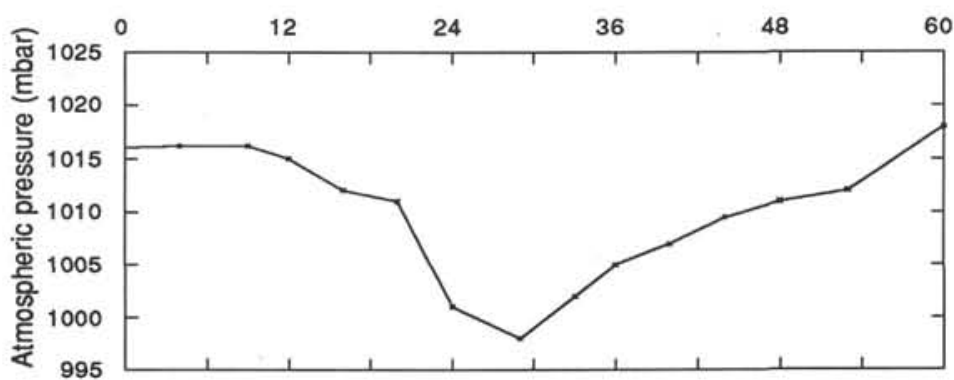

B

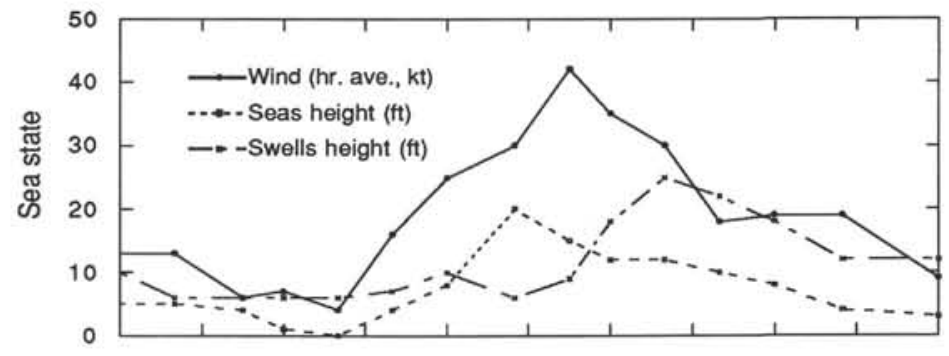

C

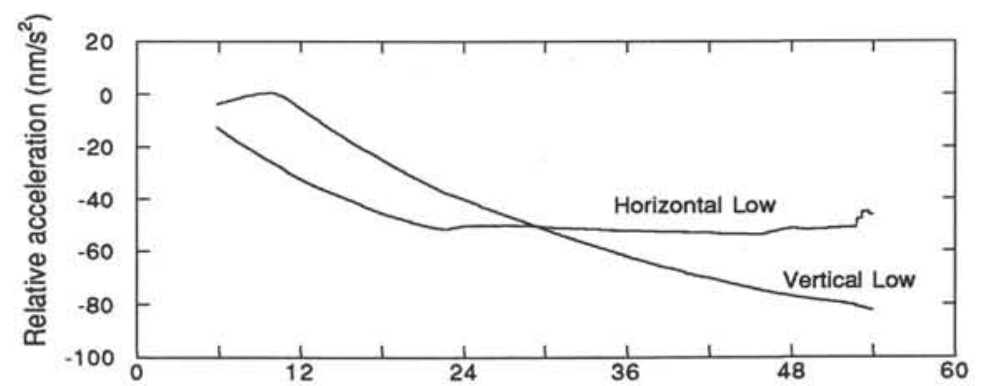

D

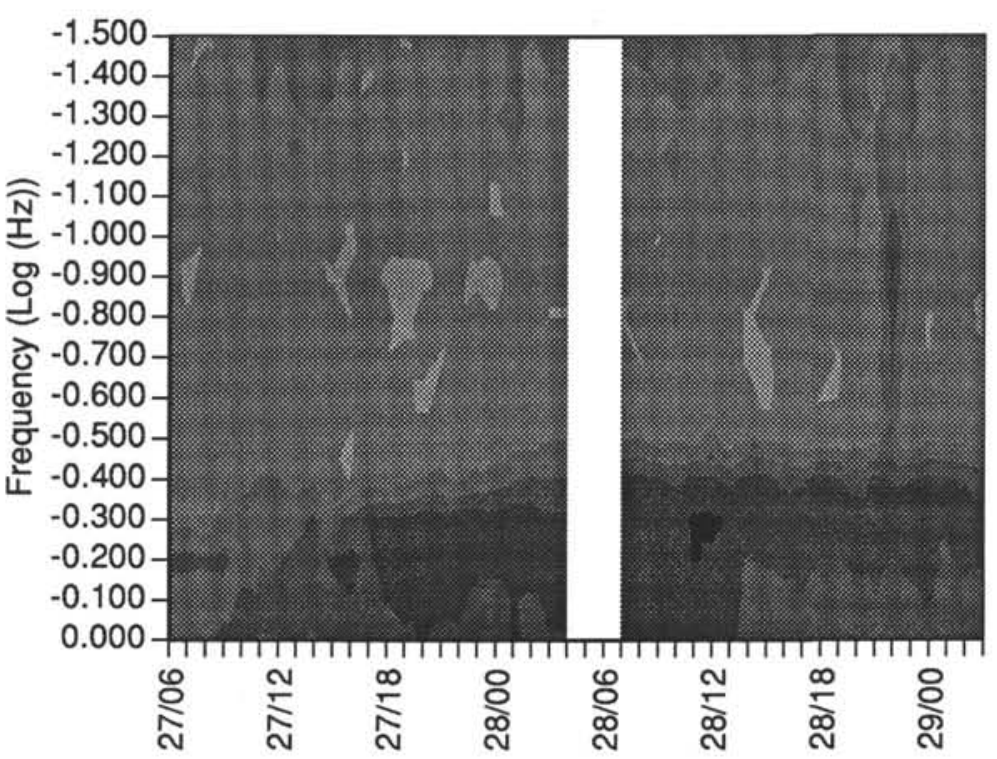

Figure 19. A. Atmospheric pressure as observed on JOIDES Resolution. A storm passed early on 28 September. B. Sea-state observation. The atmospheric pressure drop coincides with a wind speed maximum and sea-height maximum, whereas swells apparently develop with time delay. This change in weather condition affects the OBDS noise level (see D). C. Very long-period change of OBDS sensors obtained by taking averages of 4096 samples (about $51.1 \mathrm{~s}$ length). D. Temporal contour plot of acceleration power spectral density for the time period of 06:00 UT, 27 September to 03:00 UT, 29 September 1989. Data are not available between 05:00 and 07:00 UT, 28 September. The 22:00 UT, 28 September spectrum includes an earthquake signal from Burma. The noise level between 0.3 and $1 \mathrm{~Hz}$ increases with time to 11:00 UT, 28 September. 